\title{
Influence of Rhizobacterial and Agrobacterial Inoculation on Selected Physiological and Biochemical Changes of Banana Cultivar, Berangan (AAA) Plantlets
}

\author{
Maziah Mahmood (Corresponding author) \\ Department of Biochemistry, Faculty of Biotechnology and Molecular Sciences \\ Universiti Putra Malaysia, 43400, Serdang, Selangor DarulEhsan, Malaysia \\ Tel: 603-8946-6703Ｅ-mail: maziahm@biotech.upm.edu.my
}

Zuraida Abdul Rahman

Biotechnology Research centre

Malaysian Agricultural Research and Development Institute (MARDI)

G.P.O Box 12301, 50774, Kuala Lumpur, Malaysia

Tel: 60-3-8946-6703 E-mail: azuraida@mardi.gov.my

Halimi Mohd Saud

Department of Agriculture Technology Faculty of Agriculture, Universiti Putra Malaysia 43400, Seri Kembangan, Selangor DarulEhsan, Malaysia

Tel: 603-8946-4105Ｅ-mail: halimi@agri.upm.edu.my

Zulkifli Haji Shamsuddin

Department of Land Management, Faculty of Agriculture, Universiti Putra Malaysia

43400, Seri Kembangan, Selangor DarulEhsan, Malaysia

Tel: 603-8946-6990Ｅ-mail: zulsham@agri.upm.edu.my

Sreeramanan Subramaniam

School of Biological Sciences, Universiti Sains Malaysia

Minden Heights, 11800 Penang, Malaysia

Tel: 604-653-3528Ｅ-mail: sreeramanan@usm.my

This project is financed by Ministry of Science, Technology and Innovation (MOSTI), Malaysia (Sponsoring information)

\begin{abstract}
A series of experiments were carried out to observe the effects of rhizobacterial and agrobacterial inoculation, singly or combined on the total content, concentration and distribution of the biochemical components (total soluble protein, soluble nitrogen, proline, peroxidase activity, total soluble phenolic, nitrate reductase activity, nitrate, chlorophyll), physiological characteristics (percentages of growth, number of roots, fresh and dry weight of roots, maximum and total length of roots) and mineral contents (N, P, K, Ca and Mg) of in vitro banana plantlets, Berangan cultivar (AAA) using MS basal medium. The aims of this study are to determine the influence of various rhizobacteria sp. and Agrobacteria sp. inoculation, singly and combined on biochemical and physiological changes of the important banana plantlets in Malaysia, Berangan cultivar (AAA).Results from the inoculation study using MS basal medium were indicated that
\end{abstract}


inoculation with rhizobacteria (Azospirillum brasilense Sp7, Bacillus sphaericus UPMB10 and Microbacterium oxydens UPMB11) or agrobacteria (Agrobacterium rhizogenes strains, AR9402 and A4) showed positive response on growth of in vitro banana plantlets compared to uninoculation after one month of experiment. The inoculation treatments also increased the number of root, fresh and dry weight of roots and total length of root. In addition with inoculation, the total content or concentration of the respective biochemical activity as total soluble protein, peroxidase, nitrate reductase, proline, nitrate, soluble nitrogen, phenolic and chlorophyll of the host plants increased and varied according to the type of bacteria used. Inoculation with these bacterial also enhanced the accumulation of $\mathrm{N}$ and $\mathrm{P}$ in the banana plantlets. Co-inoculation with rhizobacteria (Azospirillum brasilense Sp7, Bacillus sphaericus UPMB10 and Microbacterium oxydens UPMB11) and agrobacteria (Agrobacterium rhizogenes strains AR9402 and A4) also showed similar response as in single inoculation; UPMB10+AR9402 treatment was the most effective treatment. The above finding provided evidence that Azospirillum brasilense Sp7, Bacillus sphaericus UPMB10, Microbacterium oxydens UPMB11, Agrobacterium rhizogenes strains AR9402 and A4, singly or combined are potentially effective in promoting growth of in vitro banana plantlets. Inoculation of rhizobacteria was showed beneficial to the banana plantlet in saline conditions through increment of growth and improvement in rooting system. Thus, these bacterial strains could be used as a bioenhancer for growth of in vitro banana plantlets.

Keywords: Rhizobacterial, Agrobacterial, Banana, Physiology, Biochemical

\section{Introduction}

Challenges faced by the banana industries from globalization are a result of lack of increased production and productivity, absence of economical scale of production, higher cost of inputs and low levels of technology used in the production system. Rhizobacteria that exert beneficial effects on plant growth and development are referred to as plant growth-promoting rhizobacteria (PGPR).

The use of PGPR to promote plant growth has increased in various parts of the world. PGPR can affect plant growth by producing and releasing secondary metabolites and facilitate the availability and uptake of certain nutrients from the root environment (Zahir et al., 2003). A promising trend for increasing the efficiency of nitrogen fixing bacteria could be used naturally or through artificial mixtures of microorganisms (Okon and Labandera-Gonzalez, 1994). Herbaspirillum seropedicae is a nitrogen-fixing bacteria found in association with economically important plants (Bashan et al., 2000).

Inoculation with Azospirillum halopraeferens, a mixture of two Azospirillum brasilense strains, a mixture of Bacillus licheniformis and Phyllobacterium sp. has significantly increased plant height and dry weight of oilseed (Salicornia bigelovii) (Bashan et al., 2000). Co-inoculation is based on mixed culture inoculation, combinations of microorganisms that interact synergistically, or when rhizobacteria is functioning as a 'helper' bacterium to enhance the performance of other beneficial microorganisms. Co-inoculation of a Pseudomonas sp. with Mesorhizobium strain (Ca181) has shown a significant increase in nodule weight and shoots biomass of Vigna radiata, when grown in sterilized condition (Sindhu et al., 2002). The objectives of this study are to determine the influence of various rhizobacteria sp. and Agrobacteria sp. inoculation, singly and combined on biochemical and physiological changes of the important banana plantlets in Malaysia, Berangan cultivar (AAA).

\section{Materials and methods}

\subsection{Plant materials}

Banana plantlets cv. Berangan (AAA) established in a standard MS solid medium (Murashige and Skoog, 1962). One-month-old plantlets were cultured in $30 \mathrm{~mL}$ modified MS liquid medium at $\mathrm{pH} 5.7$ using $100 \mathrm{~mL}$ Erlenmeyer flasks. The cultures were incubated on an orbital shaker at 80rpm and were exposed to continuous fluorescent light at $27^{\circ} \mathrm{C} \pm 1^{\circ} \mathrm{C}$ for a month. The one-month duration was sufficient for plantlets to absorb all nutrients that were available in the media. The $30 \mathrm{~mL}$ MS liquid medium was replenish with fresh medium at two week intervals.

\subsection{Bacterial cultures}

Rhizobacterial and agrobacterial cultures were used in this experiment. The treatments were: inoculated, singly or combined with $1 \mathrm{~mL}$ of different species of rhizobacteria and agrobacteria into the MS liquid media at $1 \times 10^{7}-1 \times 10^{8}$ $\mathrm{cfu} / \mathrm{mL}\left(\mathrm{OD}_{600 \mathrm{~mm}}\right)$ concentrations.

Experiments were divided into three sequential experiments; inoculated singly with rhizobacteria (Experiment A), or agrobacteria (Experiment B) and combined (rhizobacteria and Agrobacteria) (Experiment C). The medium were inoculated with different species of rhizobacterial and agrobacterial, singly or combined at $1 \times 10^{7}-1 \times 10^{8} \mathrm{cfu} / \mathrm{mL}$ $\left(\mathrm{OD}_{600 \mathrm{~nm}}\right)$ concentrations.

Experiment A: The three species of rhizobacterial used were: Azospirillum brasilense Sp7, Bacillus sphaericus UPMB10 and Microbacterium oxydens UPMB11. The non-inoculated treatment was used as a control. 
Experiment B: The four different strains of agrobacterial used were: Agrobacterium rhizogenes strains AR9402, A4, 16758 and 14356. The non-inoculated treatment was used as a control.

Experiment C: Co-inoculation (mixed cultures) treatment of the rhizobacteria and agrobacteria were carried out using Azospirillum brasilense Sp7, Bacillus sphaericus UPMB10 or Microbacterium oxydens UPMB11 mixed with Agrobacterium rhizogenes strains AR9402 or A4. A single inoculated treatment using Bacillus sphaericus UPMB10 and non-inoculated treatment were used as controls.

Plantlets that have been inoculated with the respective bacterial treatments were placed on orbital shaker $(80 \mathrm{rpm})$ at $27 \pm 1^{\circ} \mathrm{C}$ under continuous florescent light. Physiological parameters recorded include plant growth, number, fresh and dry weight and maximum and total length of roots.

Similarly, biochemical changes such as total soluble protein content (Bradford, 1976), soluble nitrogen Speis (1957), proline (Bates, 1973), peroxidase activity, total soluble phenolic content, nitrate reductase activity (Andrew et al., 1992), nitrate content, and chlorophyll content (Harbone, 1973) after one month of culture. To determine the percentage of N, $\mathrm{P}$ and $\mathrm{K}$ in plantlets, Digesdahl Digestion Apparatus Methods were used. The whole plantlets were dried at $60^{\circ} \mathrm{C}$ for 2 or 3 days and their weights were recorded. A $0.2 \mathrm{~g}$ of samples was grinded. The samples (dry plantlets) were put into a $100 \mathrm{ml}$ digestion flask. A $5 \mathrm{ml}$ of concentrated sulphuric acid $\left(\mathrm{H}_{2} \mathrm{SO}_{4}\right)$ was added into the digestion flask and swirled to get an even mixture. Meanwhile, the digesdahl apparatus were set at $44^{\circ} \mathrm{C}$. The samples were heated until white smoke disappeared or after 5 to 10 minutes. A $5 \mathrm{ml}$ of hydrogen peroxide $\left(\mathrm{H}_{2} \mathrm{O}_{2}\right)$ was added and digestion continued until the boiling ceased and clear samples were obtained indicative of complete digestion. The samples were removed from the digestion apparatus to cool and the volumes were adjusted to a final $100 \mathrm{ml}$ with distilled water. The solution was then filtered using Whatman Paper No. 42 and collected in plastic vials. The N and P concentration were determined by using auto analyser apparatus. The samples were taken directly from the filtrate. For K determination, the filtrate needs to be diluted to 25 times. The samples for $\mathrm{K}$ concentration were determined using the flame photometer. All the nutrients determination was carried out in the Analytical Laboratory, Department of Land Management, and Faculty of Agriculture UPM.

\subsection{Statistical analysis}

The experimental were set up with 10 replicates and repeated twice. The result were compared by ANOVA and tested by Duncan's multiple range test to find the differences between treatment means at the 5\% (0.05) significant level. Data were analyzed using the general Statistical Analysis system (SAS).

\section{Results and discussion}

\subsection{Growth and root biomass}

In experiment $A$, single inoculation with rhizobacterial species experienced an increase in growth of the plantlets, number, fresh and dry weight, and total length of roots of in vitro banana plantlets (Figure 1). Results showed that single inoculation with UPMB10 had the highest increase in growth of plantlet at $172 \%$ (control is $119 \%$ ) (Figure 1a;2). Inoculation with UPMB11 also showed an increase up to $35.3 \%$ but Sp7 did not produce a significant increase (4.2\%) when compared to the control. The results showed that rhizobacterial species UPMB10 and UPMB11 have the ability to increase plant growth under in vitro conditions after one month of treatment.

\section{Figure 1}

\section{Figure 2}

Inoculation with all three species of rhizobacteria increased the root number of banana plantlets compared to the control (Figure $1 \mathrm{a}$-b). Inoculation with Sp7 gave the highest increment at 7, followed by UPMB11 and UPMB10 treatments, both gave similar increment, 5 . The root fresh weight also showed an increase when inoculated with Sp7 and UPMB11 at $0.78 \mathrm{~g}$ and $0.79 \mathrm{~g}$, respectively (Figure $1 \mathrm{a}-\mathrm{c}$ ). Inoculation with UPMB10 showed no change in weight compared to the control. Inoculation with UPMB11 showed an increase in root dry weight at $40.3 \mathrm{mg}$ while the other treatments showed no change in weight compared to the control (Figure $1 \mathrm{a}-\mathrm{d}$ ). The maximum root length showed a significant $(\mathrm{P}<0.05)$ increase only in UPMB10 treatment at $29.5 \mathrm{~cm}$ while the others showed no significant change (Figure a-e). The total root lengths showed an increase only in UPMB11 and UPMB10 treatments at 47 and $46.3 \mathrm{~cm}$, respectively, compared to control while $\mathrm{Sp} 7$ produced no significant $(\mathrm{P}<0.05)$ change (Figure 2).

In Experiment $\mathrm{B}$, inoculation with agrobacterial on in vitro banana plantlets showed inherent effects in enhancing growth of the host plant. The growth of plantlets and root biomass as number, fresh and dry weight of roots, maximum and total lengths of root are shown in Figure 3. Generally, inoculation with strains of AR9402 and A4 showed increased growth of plantlets (211-181\%) (Figure 3) compared to the control. In addition plantlets treated with agrobacterial strains 15834 and 8189 exhibited growth within a range 43-61\%, significant lower than the control (Figure 4). Sindhu et al. (2002) reported that production of toxic metabolites with an inhibitory effect on growth of roots by non-fluorescent Pseudomonads. 


\section{Figure 3}

\section{Figure 4}

The experiment has shown that inoculation of agrobacteria especially from strain AR9402 and A4 have the potential to stimulate growth and root biomass of the host plant. Inoculation of Agrobacterium strains AR9402 and A4 have shown inherent effect in stimulating growth and rooting system of the in vitro banana plantlets. It is well established that Agrobacterium species play an important part in promoting rooting system of plants. Based on the results, it is interesting to highlight that the association of agrobacteria (strain AR9402 and A4) and plantlets have successfully enhanced growth and rooting system of the host plant. According to Freitas et al. (1997), the most common bacteria associated with roots of field crops were bacilli (34\%) and pseudomonads (17\%), with the most abundant being B.brevis, B. licheniformis, B. megaterium and B. sphaericus.

In Experiment $\mathrm{C}$, the combined treatments of rhizobacteria and agrobacteria were tested in association with in vitro banana plantlets. The data of six combined inoculation treatments with rhizobacterial and agrobacterial on plant growth, number, fresh and dry weight, maximum and total length of roots are shown in Table 1. The plant growth highest in UPMB10+A4 (685.5\%) treatment, followed by UPMB11+AR (673\%), UPMB11+A4 (641\%) and UPMB10+A4 (435.5) treatments. The Sp7+AR (409\%) treatment showing no change compared to control (Table 1).

\section{Table 1}

These results suggested that rhizobacteria (UPMB10 and UPMB11) acted synergistically with agrobacteria (AR940 and A4) and were effective in promoting growth of the plantlets. Thus, these rhizobacteria could be exploited as co-inoculants with agrobacteria for better plant growth. Similar results were obtained by Shindu et al. (2002) with co-inoclulation of Pseudomonas strain and Mesorhizobium which stimulated nodule fresh weight and plant dry weight. Thus, combination of rhizobacteria and agrobacteria should be evaluated since they may have a potential as future inoculants

\subsection{Total soluble protein}

Total soluble protein in leaves and roots increased after inoculation with $\mathrm{Sp} 7$ and UPMB10 with no change observed for UPMB11 treatment, compared to control (Figure 5). The total soluble proteins in leaves for both Sp7 and UPMB10 are much higher than in roots with those for leaves at $15.0 \mathrm{mg} / \mathrm{gfw}$ and $19.0 \mathrm{mg} / \mathrm{gfw}$ and for roots at $14.0 \mathrm{mg} / \mathrm{gfw}$ and 15.8 $\mathrm{mg} / \mathrm{gfw}$, respectively.

Total soluble protein content in leaves and roots were also markedly increased by inoculation with agrobacterial strains AR9402 and A4 but showed a reduction with strains 15834 and 8189 . The total soluble proteins in leaves for both agrobacteria strains AR9402 and A4 are much higher than in roots with those for leaves at $24 \mathrm{mg} / \mathrm{gfw}$ and $25 \mathrm{mg} / \mathrm{gfw}$ and for roots at $16.6 \mathrm{mg} / \mathrm{gfw}$ and $18.9 \mathrm{mg} / \mathrm{gfw}$, respectively. It was observed that the soluble protein increased only in treatment inoculated with agrobacteria strains AR9402 and A4, which showed similar trend in growth and root biomass of plantlets as shown in Figure 5b.

The highest leaf protein content was obtained from plantlets that were co-inoculated with different species of rhizobacterial and agrobacterial. It was UPMB10+AR treatment $(20 \mathrm{mg} / \mathrm{gfw})$ followed by UPMB11+AR $(19.8 \mathrm{mg} / \mathrm{gfw})$, UPMB11+A4 (18.96 mg/gfw) and UPMB10+A4 (18 mg/gfw) treatments (Figure 5c). Similar trends were observed in root protein of plantlets whereby, UPMB10+AR treatment showed the highest in root protein at $19.5 \mathrm{mg} / \mathrm{gfw}$ compared to other treatments.

\section{Figure 5}

The results showed that the combined inoculation of rhizobacteria and agrobacteria affected the amount of total soluble protein of plantlets. Combined inoculation with UPMB10 and agrobacterial strains AR9204 produced superior result in protein content compared to other treatments. The increase of total protein content of plantlets could be related to the enhancement of root growth and stimulation on nutrient uptake.

\subsection{Soluble nitrogen}

Inoculation with three species of rhizobacterial into the media did not produce a significant increase in leaf soluble nitrogen content of plantlets when compared to the control (Figure 6). Inoculation with UPMB10 showed the highest increase in root soluble nitrogen content which increased up to $23.2 \%$, followed by Sp7 and UPMB11 treatments at $21.5 \%$ and $20.3 \%$, respectively (Figure 6a). The results showed that all species of rhizobacterial have the ability to increase soluble nitrogen content of banana plantlets only roots, not in leaves.

\section{Figure 6}

Inoculation with agrobacterial strains A4 showed the highest soluble nitrogen content of in vitro banana plantlets in both leaves and roots at $389 \mu \mathrm{g} / \mathrm{gfw}$ and $235 \mu \mathrm{g} / \mathrm{gfw}$, respectively. Inoculation with agrobacterial srains AR9402 also show significant increase in leaves and roots soluble nitrogen content of plantlets at $345 \mu \mathrm{g} / \mathrm{gfw}$ and $213 \mu \mathrm{g} / \mathrm{gfw}$ 
compared to the control. But those with treatment 15834 (leaves: $150.0 \mu \mathrm{g} / \mathrm{g}$ fw, root: $98.6 \mu \mathrm{g} / \mathrm{g} \mathrm{fw}$ ) and 8189 (leaves: $180.0 \mu \mathrm{g} / \mathrm{g} \mathrm{fw}$, roots: $99.5 \mu \mathrm{g} / \mathrm{g} \mathrm{fw}$ ) showed significantly lower than the control (Figure $6 \mathrm{~b}$ ). These phenomena indicated the ability of the inocula tested, Agrobacterium rhizogenus strain AR9402 and A4 to increase the content of soluble nitrogen of the in vitro banana plantlets

An increase was also observed in treatments of UPMB11+AR, UPMB11+A4 and UPMB10+A4 (Figure 6c). These results indicated that combined inoculation treatments directly affect the soluble nitrogen content of plantlets, as physiological effects (percentages of growth, number of roots, fresh and dry weight of roots, maximum and total length of roots). The mechanism of growth promotion by co-inoculation is not well understood; however a wide range of possibilities have been postulated including an increase in insoluble nutrient and subsequent enhancement in uptake capacity by plant which eventually will stimulate plant growth (Bashan and Holguin, 1995).

\subsection{Proline}

Inoculation with rhizobacteria showed dramatic decrease in proline content of roots for all species compared to control (Figure 7). The descending order of effect of rhizobacterial inoculation on root proline content: UPMB11>Sp7>UPMB10 with values of $58 \mathrm{ug} / \mathrm{gfw}, 45.6 \mu \mathrm{g} / \mathrm{gfw}$ and $34.2 \mu \mathrm{g} / \mathrm{gfw}$ compared to control at $126.7 \mu \mathrm{g} / \mathrm{gfw}$ (Figure 7a). There is an increase in proline content of leaves for Sp7 treatment at $49.7 \mu \mathrm{g} / \mathrm{gfw}$ compared to control at $35.0 \mu \mathrm{g} / \mathrm{gfw}$.

\section{Figure 7}

Plants inoculated with agrobacterial strains 15834 and 8189 showed higher proline content compared to the control in both leaves and roots within a range 77-85 $\mu \mathrm{g} / \mathrm{gfw}$ and $178-241 \mu \mathrm{g} / \mathrm{gfw}$, respectively (Figure $7 \mathrm{~b}$ ). High accumulation of proline content in the treatment inoculated with agrobacterial strains 15834 and 8189 could be related indirectly to the inoculation process retarding root growth and development of the plantlets. Similar reports have been shown by Wang et al. (1999) that a decrease in growth rate was accompanied by an increase in proline level. Proline is considered to be involved in osmotic adjustment (Wang et al., 1999). The beneficial role of proline in plant stress tolerance demonstrated that proline can increase the tolerance of plant to abiotic stress (Saleena et al., 2002).

Combined inoculation of rhizobacteria (Sp7) and agrobacteria (strains AR9402 or A4) showed a higher level of proline content in both leaves and roots compared to other treatments. The distribution of proline accumulation was more in the roots rather than leaves since the roots are in contact with the medium and inocula. Proline content of leaves of the plantlets treated with $\mathrm{Sp} 7+\mathrm{A} 4$ and $\mathrm{Sp} 7+\mathrm{AR}$ was higher compared to other treatments at $78.4 \mu \mathrm{g} / \mathrm{mg}$ protein and 91.4 $\mu \mathrm{g} / \mathrm{mg}$ protein, respectively. For other treated plantlets, the leaf proline content was within a range $31.0-44.0 \mu \mathrm{g} / \mathrm{mg}$ protein with the control at $39.0 \mu \mathrm{g} / \mathrm{mg}$ protein. Similar result were observed in roots of plantlets: Sp7+A4 treatment showed the highest proline content at $181.8 \mathrm{ug} / \mathrm{mg}$ protein followed by Sp7+AR9402 treatment at $167.4 \mu \mathrm{g} / \mathrm{mg}$ protein and other treatments within a range $29.0-65.0 \mu \mathrm{g} / \mathrm{mg}$ protein and control at $151.8 \mu \mathrm{g} / \mathrm{mg}$ protein (Figure $7 \mathrm{c}$ ). Based on the result on plant growth, combined inoculation of Sp7 with AR9402 or A4 showed inhibited plant growth (Table 1).

\subsection{Peroxidase activity}

Peroxidase activity after inoculation with UPMB10 showed an increase to $1896 \mathrm{U} / \mathrm{mg}$ protein in leaves and to 3897 $\mathrm{U} / \mathrm{mg}$ protein in roots compared to the control (Figure 8). Treatment with other species did not show significant change in peroxidase activity compared to the control in both leaves and roots. Plant peroxidase can reinforce the cell wall through the deposition of several cell wall components such as lignin, suberin and extensin (Lagrimini, 1996).

\section{Figure 8}

Leaves of plantlets inoculated with agrobacterial strains 8189 showed highest peroxidase activity at $5136 \mathrm{U} / \mathrm{mg}$ protein, followed by plants inoculated with agrobacterial strains 15834, AR9402 and A4 at $2400 \mathrm{U} / \mathrm{mg}$ protein, $3001 \mathrm{U} / \mathrm{mg}$ protein and $1900 \mathrm{U} / \mathrm{mg}$ protein, respectively compared to the control at $2500 \mathrm{U} / \mathrm{mg}$ protein. Similarly in root, the peroxidase activities were higher in the presence of agrobacteria in medium to within a range $5647-9230 \mathrm{U} / \mathrm{mg}$ protein with the control (without agrobacteria) at $3463 \mathrm{U} / \mathrm{mg}$ protein (Figure $8 \mathrm{~b}$ ). The precise function of peroxidase in plant growth, development and stress tolerance remained unclear though evidence indicated that peroxidase is involved in host defense and stress induced lignification (Lagrimini et al., 1996).

The data presented in Figure 8c show the combined inoculation of rhizbacteria and agrobacteria on peroxidase activity of plantlets. Highest peroxidase activity was observed in UPMB10+ AR9204 treatment in both leaves and roots at 3514 $\mathrm{U} / \mathrm{mg}$ protein and $9423 \mathrm{U} / \mathrm{mg}$ protein, respectively. Combined inoculation of rhizobacteria $\mathrm{Sp} 7$ with agrobacterial strains AR9204 or A4 showed a decrease in peroxidase activity compared to uninoculated or single inoculation of banana plantlets.

\subsection{Phenolic compound}

Inoculation with rhizobacteria showed an increase in phenolic content of roots and leaves of plantlets compared to the control (Figure 9). In roots, UPMB10 treatment showed the highest in total soluble phenolic at $63.07 \mu \mathrm{g} / \mathrm{gfw}$ followed 
by the UPMB11 and SP7 treatments at $61.5 \mu \mathrm{g} / \mathrm{gfw}$ and $56.5 \mu \mathrm{g} / \mathrm{gfw}$, respectively compared to control which was only at $55.25 \mu \mathrm{g} / \mathrm{gfw}$ (Figure 9a). Similar results were obtained in leaves of plantlet, which UPMB10 gave at $27 \mathrm{mg} / \mathrm{gfw}$, UPMB11; $15.7 \mathrm{mg} / \mathrm{gfw}$ and SP7; $11.2 \mathrm{mg} / \mathrm{gfw}$ and control was only at $10 \mathrm{mg} / \mathrm{gfw}$.

\section{Figure 9}

The total soluble phenolic in roots for both treatment, AR9402 and A4 are much higher than in leaves at $76.4 \mathrm{mg} / \mathrm{gfw}$ and $84.9 \mathrm{mg} / \mathrm{gfw}$ foor roots and at $13.0 \mathrm{mg} / \mathrm{gfw}$ and $15.7 \mathrm{mg} / \mathrm{gfw}$ for leaves, respectively (Figure $9 \mathrm{~b}$ ). This result clearly demonstrated that both agrobacteria strains AR9402 and A4 could induce total phenolic compound especially in roots in association with banana plantlets under tissue culture condition. Report has shown that growth and accumulation of phenolic compounds are generally inversely related by altering the mineral uptake, water relation, photosynthesis, carbon flow, and phytohormone activity (Iosipenko and Ignatov, 1995).

\subsection{Nitrate reductase activity (NRA)}

Figure 10 shows NR activity in both leaves and roots of plantlets inoculated with rhizobacteria. Generally, there was an increase in NR activity for all treatments. The UPMB10 treatment showed the highest increment of NR activity in root at $0.2 \mathrm{U} / \mathrm{mg}$ protein. In leaves, the highest activity was showed by $\mathrm{Sp} 7$ treatment at $0.01 \mathrm{U} / \mathrm{mg}$ proteins. The descending orders of effectiveness of rhizobacteria were: UPMB10 $>$ UPMB11 $>$ Sp7 for leaves and UPMB10 $>$ Sp7 $>$ UPMB11 for roots. This study indicated that NR activity in leaves and root of plantlets increased when plantlets were grown in a media containing rhizobacteria.

\section{Figure 10}

In the subsequent analysis, the range of NR activity of plantlets inoculated with agrobacteria showed higher activities than those uninoculated. In roots, inoculation process showed an increase in NR activity of plantlets. The inoculation treatment showed a higher NR activity plantlets compared to control with a range $0.05-0.24 \mathrm{U} / \mathrm{mg}$ of protein (control at $0.01 \mathrm{U} / \mathrm{mg}$ protein). The highest was observed in AR9402 treatment at $0.24 \mathrm{U} / \mathrm{mg}$ protein. However, in leaves the NR activity was higher only in AR9402 and A4 treatments at $0.01 \mathrm{U} / \mathrm{mg}$ protein and $0.02 \mathrm{U} / \mathrm{mg}$ protein, respectively (Figure 10b). Nitrate reductase is a substrate - inducible enzyme and is thought to be the most limiting step in $\mathrm{N}$ assimilation. For this reason, NR activity could be selected for yields and $\mathrm{N}$ assimilation potential (Li and Oaks, 1993). The $\mathrm{NO}_{3}{ }^{-}$reduction is controlled primarily by the rate of $\mathrm{NO}_{3}{ }^{-}$uptake, rather than by alterations in $\mathrm{NR}$ activity or limitations in reducing power (Wilkinson and Crawford, 1993).

Figure 10c shows the effect of combined inoculation of rhizobacteria and agrobacteria on NR activity in leaves and root of the banana plantlets. Leaves NR activity was the highest in UPMB10+AR treatment at $0.25 \mathrm{U} / \mathrm{mg}$ protein and followed by treatment of UPMB11+AR $(0.20 \mathrm{U} / \mathrm{mg}$ protein), UPMB11+A4 (0.13 U/mg protein), UPMB 10+A4 $(0.12$ $\mathrm{U} / \mathrm{mg}$ protein) and $\mathrm{Sp} 7+\mathrm{AR}(0.12 \mathrm{U} / \mathrm{mg}$ protein).

\subsection{Nitrate}

Results showed that the nitrate content in leaves was much higher than that of roots (Figure 11). Inoculation of rhizobacteria showed nitrate is higher compared to uninoculated. The treatment that consists of rhizobacteria showed a higher content of nitrate compared to uninoculated in all parts of the plantlets. Results from Figure 11a shows the increase in the nitrate content of leaves in all the treatments of rhizobacteria species compared to control with UPMB11 giving the highest increment at $38.7 \mathrm{mg} / \mathrm{gfw}$ followed by UPMB10 and Sp7 treatments at $36.8 \mathrm{mg} / \mathrm{gfw}$ and $33.7 \mathrm{mg} / \mathrm{gfw}$, respectively. Similarly in root, which UPMB10 shows the highest increment in nitrate content at $108.7 \mathrm{mg} / \mathrm{gfw}$ followed by UPMB11 and Sp7 treatments at $80.6 \mathrm{mg} / \mathrm{gfw}$ and $71.0 \mathrm{mg} / \mathrm{gfw}$. The descending order of effectiveness of rhizobacteria was: UPMB11>UPMB10>Sp7 for leaves and UPMB10 > UPMB1 $>$ Sp7 for roots.

\section{Figure 11}

Nitrate accumulation for respective plantlets was influenced by different inoculation treatments. The highest results in nitrate content of plantlets were shown in treatment of AR9402 followed by A4 treatment in both leaves and root. The results shown were within the range of $39.0-42.0 \mathrm{mg} / \mathrm{gfw}$ in leaves and $51.0-54.0 \mathrm{mg} / \mathrm{gfw}$ in root (Figure 11b). The nitrate content in leaves and roots increased in combined treatments containing UPMB10 or UPMB11 combined either with agrobacteria strains AR or A4. The highest nitrate content in leaves and root was in UPMB11+AR (69.8 $\mathrm{mg} / \mathrm{gfw})$ and UPMB11+A4 $(126.3 \mathrm{mg} / \mathrm{gdw})$ treatments, respectively. The data presented in Figure 4.8-c reveal that combined inoculation of rhizobacteria and agrobacteria showed positive effect on quantities of nitrate content in leaves and root of banana plantlets especially both agrobacteria, strains AR9402 or A4 combined with UPMB10 or UPMB11.

Results showed that nitrate content was higher in combined treatments when compared to the control or single inoculation especially in root. The increase in nitrate content of banana plantlets is probably due to an increase in NR activity in the plantlets. The promotion of plant growth by PGPR for most parts of the plants has provided the plant with a compound that is synthesized by the bacterium to facilitate the uptake of certain nutrient from the environment (Glick, 1995). 


\subsection{Chlorophyll}

Results from Figure 12 showed the total chlorophyll content of plantlets inoculated with rhizobacteria was higher compared to the control. UPMB10 treatment giving the highest of chlorophyll content at $7.5 \mathrm{mg} / \mathrm{gfw}$ followed by UPMB11 and Sp7 treatments at $6.4 \mathrm{mg} / \mathrm{gfw}$ and $5.2 \mathrm{mg} / \mathrm{gfw}$, respectively. There was a positive response of inoculation in promoting chlorophyll content of plantlets

\section{Figure 12}

Total chlorophyll content in leaves was increased after inoculated with agrobacteria strains AR94027 and A4 (Figure 12). However, the total chlorophyll was reduced in plantlet inoculated by agrobacteria strains 15834 and 8189 . The total chlorophyll content in leaves for both treatment of AR9402 and A4 was much higher than the control at $6.0 \mathrm{mg} / \mathrm{gfw}$ and $5.9 \mathrm{mg} / \mathrm{gfw}$, respectively. The chlorophyll content of plantlets inoculated with strains 15843 and 8198 shows much lower only at $0.23 \mathrm{mg} / \mathrm{gfw}$ and $0.46 \mathrm{mg} / \mathrm{gfw}$ compared to control at $4.56 \mathrm{mg} / \mathrm{gfw}$ (Figure 12b). Leaves chlorophyll content of plantlets in the combined inoculated of rhizobacteria and agrobacteria was more effective compared to the single inoculation. The UPMB10+AR9402 treatment showed the highest chlorophyll content at $6.93 \mathrm{mg} / \mathrm{gfw}$ followed by UPMB10+A4 treatment at $6.925 \mathrm{mg} / \mathrm{gfw}$ and single inoculation (UPMB10 treatment) showed only at $3.66 \mathrm{mg} / \mathrm{gfw}$ (Figure 12c).

According to Quilici and Medina (1998), photosynthetic and chlorophyll content increased linearly with leaf N content in both Crotalaria and Verbasina. De Veau et al. (1990) have reported that the mean milligram of chlorophyll content per square decimeter of Bradyrhizobium inoculated soybean (Glycine max) test leaves was about 50\% lower than the other group's leaves of control. The inoculated host plants utilized their chlorophyll more efficiently for photosynthetic $\mathrm{CO}_{2}$ uptake than control plants.

\subsection{N, P, K, Ca and Mg content}

Effects of rhizobacteria inoculation on nutrient uptake; Nitrogen (N), Phosphorus (P), Potassium (K), Calcium (Ca) and Magnesium $(\mathrm{Mg})$ content of plantlet were analyzed and presented in Figure 13. The nitrogen level in plantlets inoculated with UPMB10, UPMB11 and Sp7 showed significant increase compared to those uninoculated (control) with an increment at $5.3 \mathrm{mg} / \mathrm{gdw}, 5.1 \mathrm{mg} / \mathrm{gdw}$ and $5.13 \mathrm{mg} / \mathrm{gdw}$, respectively.

Potassium content in the plantlets inoculated with UPMB10 was highest at $5.6 \mathrm{mg} / \mathrm{gdw}$. However treatment with $\mathrm{Sp} 7$ and UPMB11 showed significant lower than the control at $3.5 \mathrm{mg} / \mathrm{gdw}$ and $3.6 \mathrm{mg} / \mathrm{gdw}$, respectively. Treatments with all species of rhizobacterial did not produce a significant change in $\mathrm{Ca}$ content of the plantlets compared to the control. According to Glick (1995), Azospirillum may increase the solubilization of minerals such as phosphorus and metal in the forms that are more readily available for plant growth. Increased mineral have been attributed to the increase in uptake to a general increase in the volume of the root system and not to any specific enhancement of the normal ion uptake mechanism (Murthy and Ladha, 1988). The plants may take up $\mathrm{N}$ more efficiently from the limited supply in the medium, resulting in lower requirement of $\mathrm{N}$ fertilizer to attain a certain yield. Supporting evidence for increased mineral uptake by inoculated roots is provided by an enhancement in proton efflux activity of wheat root inoculated with PGPR (Bashan et al., 1990). It is well known that proton efflux activity is directly related to the balance of ions in plant roots.

\section{Figure 13}

The effect of agrobacteria inoculation on nutrient uptake of plantlets such as N, P, K, Ca and Mg contents are shown in Figure 13b. Nitrogen levels in plantlets showed a significant increase after inoculation with agrobacterial strains AR9402 and A4 at $7.8 \mathrm{mg} / \mathrm{gdw}$ and $7.9 \mathrm{mg} / \mathrm{gdw}$ respectively. But those treatments with $15834(4.1 \mathrm{mg} / \mathrm{gdw})$ and 8189 $(5.3 \mathrm{mg} / \mathrm{gdw})$ did not show a significant change compared to the control. Similarly was obtained in P content, it was strongly affected in plants inoculated with agrobacterial strains AR9402 and A4. K content of plantlet was the highest in treatment inoculated with strain AR9402 $(8.09 \mathrm{mg} / \mathrm{gdw})$ followed by A4 treatment $(6.45 \mathrm{mg} / \mathrm{gdw})$. Calcium contents in plantlets inoculated with agrobacterial strains AR9402 and A4 increased up to $0.5 \mathrm{mg} / \mathrm{gdw}$ and $0.65 \mathrm{mg} / \mathrm{gdw}$, respectively, compared to the control at $0.15 \mathrm{mg} / \mathrm{gdw}$.

The effect of combined inoculation on essential nutrient distribution in leaves and roots of banana plantlets is shown in Table 2. There was an increase in N, P, and K uptake in UPMB10 and UPMB11 treatments either combined with agrobacterial strains AR or A4 when compared to the single inoculation or the control. The combined inoculation of UPMB10 with agrobacterial strains AR9402 or A4 promoted the nutrient uptake (N, P, K, and Mg) of the host plant compared to single inoculation. The result showed that treatment with UPMB10+AR gave the highest $\mathrm{N}(6.71 \mathrm{mg} / \mathrm{gdw})$, $\mathrm{P}(0.821 \mathrm{mg} / \mathrm{gdw})$ and $\mathrm{Mg}(0.32 \mathrm{mg} / \mathrm{gdw})$ uptake compared to other treatments.

\section{Table 2}




\section{Conclusion}

The experiments indicate that single inoculation with Azospirillum brasilense Sp7, Bacillus sphaericus UPMB10, Microbacterium oxydens UPMB11, Agrobacteria rhizogenes (strains AR9402 and A4) can enhance growth of in vitro banana plantlets. These bacterial strains become important to devise strategies to improve growth in tissue culture system through positive response on physiological characteristics as percentages of growth, number of roots, fresh and dry weight and total length of roots. At the same time, with inoculation the total content or the concentration of the respective biochemical activities, such as total soluble protein, peroxidase, nitrate reductase, proline, nitrate, soluble nitrogen, phenolic and chlorophyll of the host plants have increased but varied according to the type of bacteria used. The inoculation treatment also caused the increase in total $\mathrm{N}$ and $\mathrm{P}$ contents of the host plants. The combined inoculation treatment with rhizobacteria (strain UPMB10 or UPMB11) and agrobacteria (AR9402 or A4) enhanced plant growth when compared to the single inoculation. The combined inoculation has advantages over the single inoculation especially in producing higher biochemical activities of the plantlets. The combined inoculation treatment also enhanced nutrient uptake, especially $\mathrm{N}$ and $\mathrm{P}$, compared to the single inoculation and therefore, can be considered as a bioenhancer for in vitro system. The results of the study clearly showed that combined inoculation of rhizobacteria and agrobacteria is a promising technique to enhance the growth of in vitro banana plantlets.

\section{References}

Andrew, A.Z, Henson, I.E. and Hartman, A. (1992). Rapid determination of nitrate reductase activity in Sorghum bicolor. Plant and Soil, 120: 5-9.

Bashan,Y., Harrison, S.K. and Whitemoyer, R.E. (1990). Enhanced growth of wheat and soybean plants inoculation with Azospirillum brasilense is not necessarily due to general enhancement of mineral uptake. Applied and Environmental Microbiology, 56: 769-775.

Bashan, Y., Moreno, M. and Troyo, E. (2000). Growth promoting of the seawater-irrigated oilseed halophyte Salicornia bigelovii inoculated with mangrove rhizosphere bacteria and halotolerant Azospirillum spp. Biology and Fertility of Soils, 32:265-272.

Bates, L.W., Waldren, R.P., and Teare, L.D. (1973). Rapid determination of proline for water stress studies. Plant and Soil, 39: 205-207.

Bradford, M. (1976). A rapid and sensitive method for the quantification of microgram quantities of protein utilizing the principle of dye binding. Analytical Biochemistry, 72: 248-254.

De Veau, E.J., Robinson, J.M., Warmbrodt, R.D. and van Berkum, P. (1990). Photosynthesis and photosynthate partitioning in $\mathrm{N}_{2}$-fixing soybeans. Plant Physiology, 94: 259-267.

Freitas, J.R.D., Banerjee, M.R. and Germida, J.J. (1997). Phosphate-solubilizing rhizobacteria enhance the growth and yield but not phosphorus uptake of canola (Brassica napus L.). Biology and Fertility of Soils, 24:358-364.

Glick, B.R. (1995). The enhancement of plant growth by free-living bacteria. Canadian Journal of Microbiology, 41: 109-117.

Harborne, J.B. (1973). Photochemical methods. Chapmann and Hall, Ltd, London. pp: 49-188.

Iosipenko, A. and Ignatov, V. (1995). Physiological aspects of phytohormone production by Azospirillum brasilense $\mathrm{Sp}$ 7. NATO ASI Ser G 37:307-312.

Lagrimini, L.M. (1996). The role of the tobacco anionic peroxidase in growth and development. In: Obinger, C., Burner, U., Eberman, R., Penel, C., Greppin, H. (eds) Plant peroxidases: Biochemistry and Physiology, University of Geneva. pp. 235-242.

Li, X.Z. and Oaks, A. (1993). Induction and turnover of nitrate reductase in Zea mays: Influence of $\mathrm{NO}_{3}$. Plant Physiology, 102:1251-1257.

Lilo, C. (1994). Light regulation of nitrate reductase in green leaves of higer plants. Plant Physiology, 90:616-620.

Murashige, T. and Skoog, F. (1962). A revised medium for a rapid growth and bioassays with tobacco tissue cultures. Physiologia Plantarum, 15:473-497.

Murty, M.G and Ladha, J.K. (1988). Influence of Azospirillum inoculation on the mineral uptake and growth of rice under hydroponic condition. Plant Soil, 108:281-285.

Okon, Y. and Labandera-Gonzalez, C.A. (1994). Agronomic applications of Azosppirillum: an evaluation of 20 years worldwide field inoculation. Soil Biology and Biochemistry, 26:1591-1601.

Quilici, A. and Medina, E. (1998). Photosynthesis-nitrogen relationships in pioneer plants of disturbed tropical montane forest sites. Photosynthetica, 35(4):525-534. 
Saleena, L.M., Rangarajan, S. and Nair, S. (2002). Diversity of Azospirillum strains Isolated from rice plants grown in saline and nonsaline sites of coastal agricultural ecosystem. Microbial Ecology, 44:271-277.

Sindhu, S.S., Suneja, S., Goel, A.K., Parmar, N. and Dadarwal, K.R. (2002). Plant promoting effects pf Pseudomonas sp. on co inoculation with Mesorhizobium sp. Cicer strain under sterile and "wilt sick" soil condition. Applied Soil Ecology, 19:57-64.

Speies, J.R. (1957). Colorimetric procedures for amino acids. Methods in Enzymology 3:467. Academic Press, New York.

Wang, H.L, Lee, P.D, Liu, L.F. and Su, J.C. (1999). Effect of sorbitol induced osmotic stress on the changes of carbohydrate and free amino acid pools in sweet potato cell suspension cultures. Botanical Bulletin of Academic Sinica, 40: 219-225.

Wilkinson, J.K. and Crawford, N.M. (1993). Identification and characterization of a chlorate-resistant mutant of Arabidopsis thaliana with mutation in both nitrate reductase structural genes NIA1 and NAI2. Molecular and General Genetics, 239:289-297.

Zahir, Z.A., Arshad, M. and Frankenberger, W.T. (2003). Plant growth promoting rhizobacteria application and perspectives in agriculture. Advances in Agronomy, 81:97-168.

Table 1. Effect of plant growth and root biomass of in vitro banana plantlets after one month culture in MS liquid medium and co-inoculated with rhizobacteria and agrobacteria. Values are means of ten replicates with $\pm \mathrm{SD}(\mathrm{P}=0.05$, $\mathrm{n}=10)$.

\begin{tabular}{|c|c|c|c|c|c|c|}
\hline Treatment & $\begin{array}{l}\text { Percentage of } \\
\text { growth } \\
(\%)\end{array}$ & $\begin{array}{l}\text { Number of } \\
\text { roots }\end{array}$ & $\begin{array}{l}\text { Fresh } \\
\text { weight of } \\
\text { roots }(\mathrm{g})\end{array}$ & $\begin{array}{l}\text { Dry weight of } \\
\text { roots } \\
(\mathrm{mg})\end{array}$ & $\begin{array}{l}\text { Max. length } \\
\text { of } \\
\operatorname{roots}(\mathrm{cm})\end{array}$ & $\begin{array}{c}\text { Total } \\
\text { length of } \\
\text { roots } \\
(\mathrm{cm})\end{array}$ \\
\hline Control & $364.5 \pm 35.00$ & $4.6 \pm 0.50$ & $0.7 \pm 0.07$ & $32.00 \pm 5.60$ & $24.0 \pm 2.30$ & $30.0 \pm 6.50$ \\
\hline UPMB10 & $402.9 \pm 26.00$ & $6.5 \pm 0.80$ & $0.6 \pm 0.10$ & $43.4 \pm 4.50$ & $30.1 \pm 1.50$ & $45.8 \pm 2.80$ \\
\hline $\begin{array}{l}\text { UPMB10+ } \\
\text { A4 }\end{array}$ & $435.5 \pm 54.00$ & $9.5 \pm 0.40$ & $0.6 \pm 0.03$ & $41.6 \pm 6.00$ & $21.0 \pm 4.10$ & $46.4 \pm 11.0$ \\
\hline $\begin{array}{l}\text { UPMB10+ } \\
\text { AR }\end{array}$ & $685.5 \pm 26.00$ & $10.2 \pm 1.50$ & $1.1 \pm 0.11$ & $74.5 \pm 15.00$ & $35.6 \pm 1.10$ & $76.0 \pm 2.10$ \\
\hline $\begin{array}{l}\text { UPMB11+ } \\
\text { A4 }\end{array}$ & $641.0 \pm 54.00$ & $5.0 \pm 1.10$ & $0.9 \pm 0.04$ & $38.7 \pm 11.00$ & $26.7 \pm 1.20$ & $54.0 \pm 8.70$ \\
\hline $\begin{array}{l}\text { UPMB11+ } \\
\text { AR }\end{array}$ & $672.0 \pm 78.00$ & $7.5 \pm 0.50$ & $0.9 \pm 0.09$ & $70.4 \pm 5.40$ & $27.1 \pm 2.50$ & $78.9 \pm 6.50$ \\
\hline $\mathrm{SP} 7+\mathrm{A} 4$ & $323.0 \pm 25.00$ & $8.5 \pm 0.20$ & $0.3 \pm 0.09$ & $25.4 \pm 6.30$ & $11.0 \pm 4.60$ & $23.6 \pm 12.0$ \\
\hline SP7+AR & $409.2 \pm 50.00$ & $6.5 \pm 1.2$ & $0.6 \pm 0.14$ & $74.2 \pm 5.00$ & $25.1 \pm 1.50$ & $69.6 \pm 6.60$ \\
\hline
\end{tabular}


Table 2. Nutrients content $(\mathrm{mg} / \mathrm{gdw})$ of in vitro banana plantlets after one month culture in MS liquid medium co-inoculated with rhizobacteria and agrobacteria. Values are means of ten replicates with $\pm \mathrm{SD}(\mathrm{P}=0.05, \mathrm{n}=10)$.

\begin{tabular}{|l|c|c|c|c|c|}
\hline & $\begin{array}{c}\mathrm{N} \\
(\mathrm{mg} / \mathrm{gDW})\end{array}$ & $\begin{array}{c}\mathrm{P} \\
(\mathrm{mg} / \mathrm{gDW})\end{array}$ & $\begin{array}{c}\mathrm{K} \\
(\mathrm{mg} / \mathrm{gDW})\end{array}$ & $\begin{array}{c}\mathrm{Ca} \\
(\mathrm{mg} / \mathrm{gDW})\end{array}$ & $\begin{array}{c}\mathrm{Mg} \\
(\mathrm{mg} / \mathrm{gDW})\end{array}$ \\
\hline Control & $4.50 \pm 0.23$ & $0.08 \pm 0.05$ & $6.78 \pm 0.40$ & $0.19 \pm 0.10$ & $0.27 \pm 0.02$ \\
\hline UPMB10 & $4.52 \pm 0.45$ & $0.62 \pm 0.02$ & $5.14 \pm 0.35$ & $0.89 \pm 0.08$ & $0.26 \pm 0.01$ \\
\hline UPMB10+A4 & $6.07 \pm 0.11$ & $0.80 \pm 0.09$ & $7.21 \pm 0.23$ & $0.79 \pm 0.11$ & $0.31 \pm 0.02$ \\
\hline UPMB10+AR & $6.71 \pm 0.56$ & $0.82 \pm 0.05$ & $6.16 \pm 0.46$ & $0.81 \pm 0.07$ & $0.32 \pm 0.02$ \\
\hline UPMB11+A4 & $5.10 \pm 1.10$ & $0.64 \pm 0.02$ & $5.25 \pm 0.66$ & $0.84 \pm 0.10$ & $0.29 \pm 0.01$ \\
\hline UPMB 11+A4 & $6.70 \pm 0.44$ & $0.57 \pm 0.04$ & $6.06 \pm 0.45$ & $0.81 \pm 0.03$ & $0.29 \pm 0.05$ \\
\hline SP7+A4 & $4.50 \pm 0.24$ & $0.52 \pm 0.05$ & $5.01 \pm 0.13$ & $0.67 \pm 0.09$ & $0.14 \pm 0.05$ \\
\hline SP7+AR & $4.51 \pm 0.34$ & $0.49 \pm 0.07$ & $4.12 \pm 0.45$ & $0.68 \pm 0.20$ & $0.19 \pm 0.01$ \\
\hline
\end{tabular}



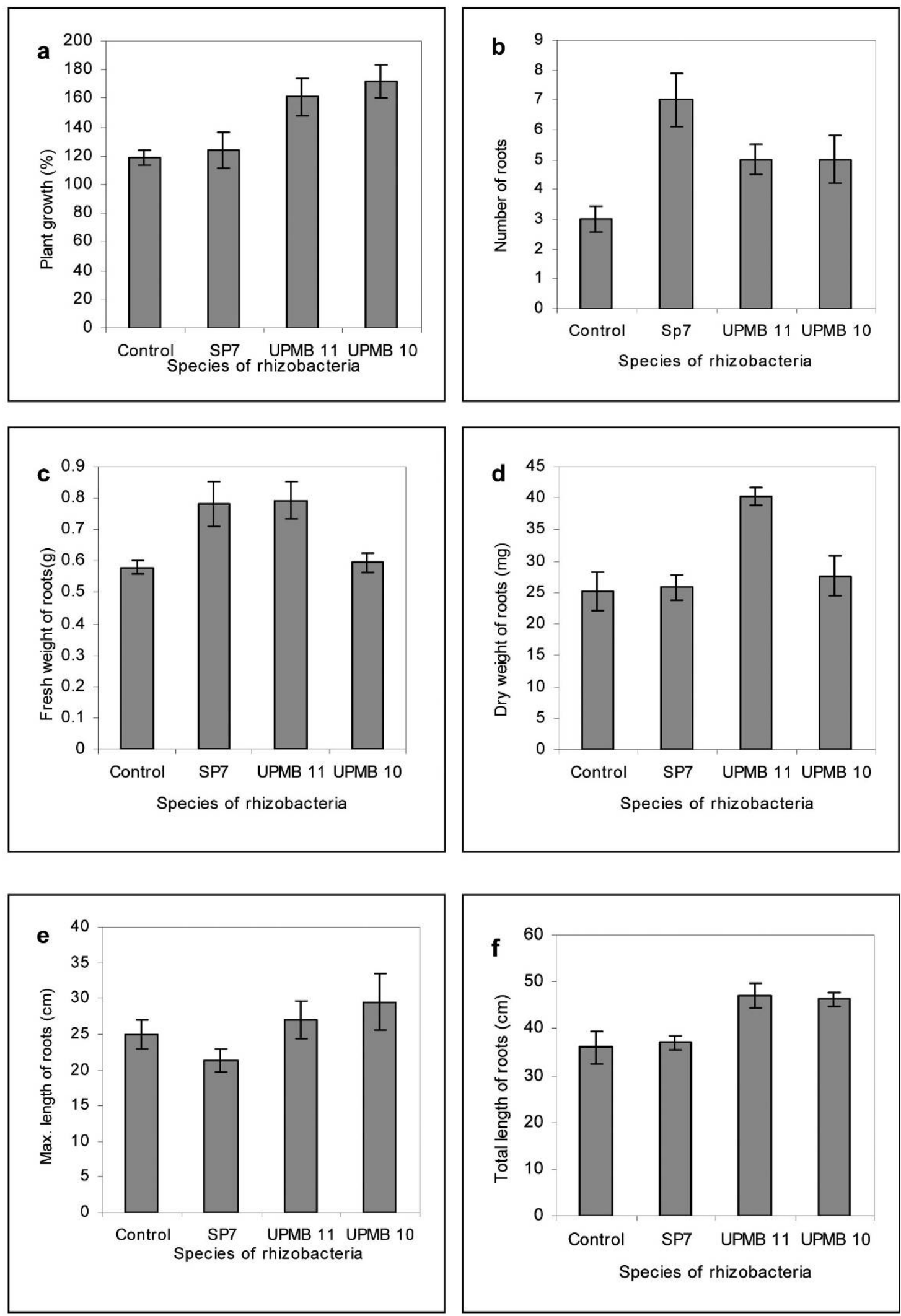

Figure 1. Growth of in vitro banana plantlets and root biomass after one month culture in MS liquid medium and inoculated with rhizobacterial species a (percentage of growth), $b$ (number of roots), c (fresh weight of roots), d (dry weight of roots), and e (maximum length of roots) and $f$ (total length of roots).Bars show means $\mathrm{SD}$ of ten replications $(\mathrm{P}=0.05, \mathrm{n}=10)$. 


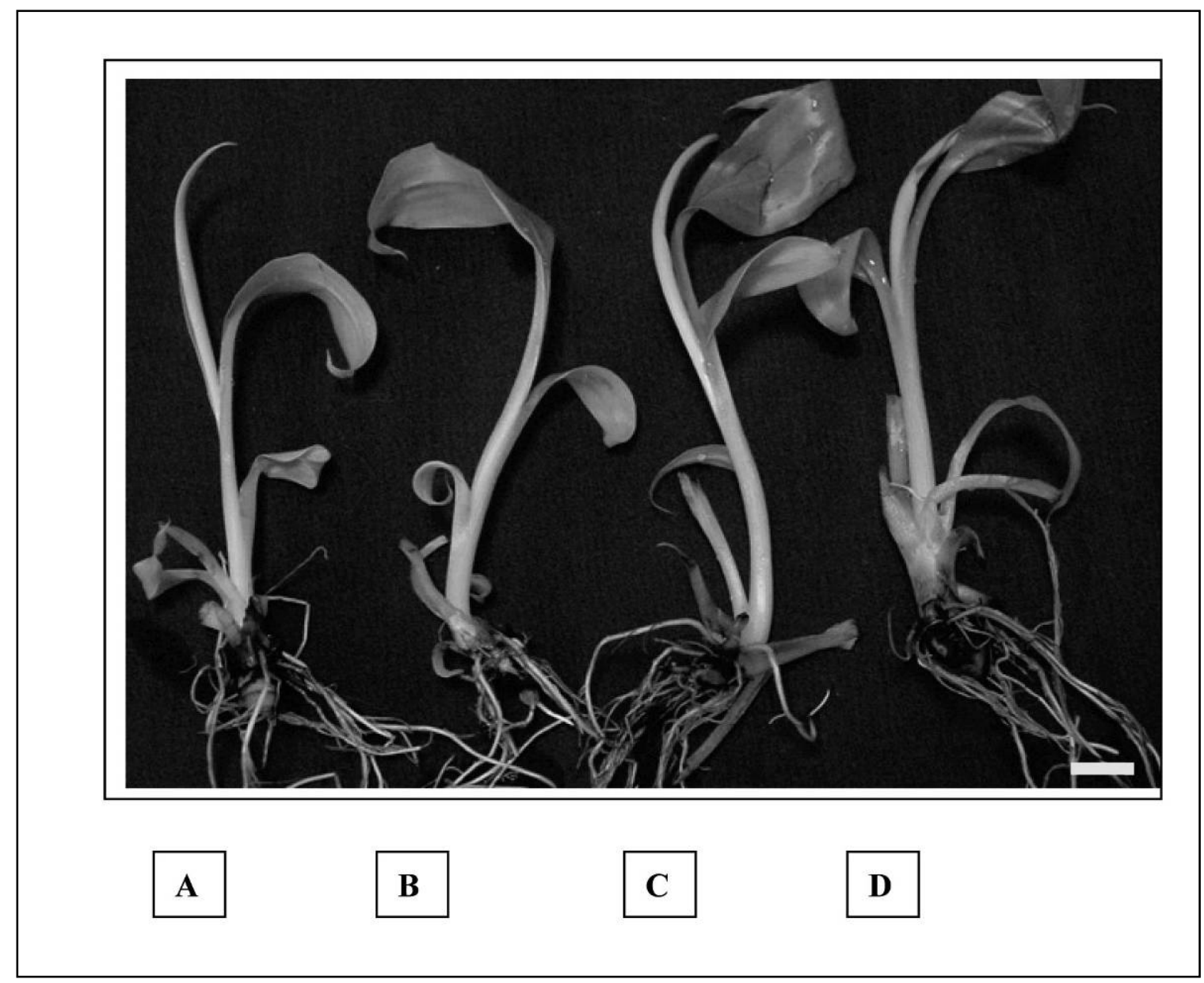

Figure 2. Growth of in vitro banana plantlets after one month culture in MS liquid medium inoculated with rhizobacterial: A (control), B (Sp7), C (UPMB11) and D (UPMB10). Bar represents 10mm. 

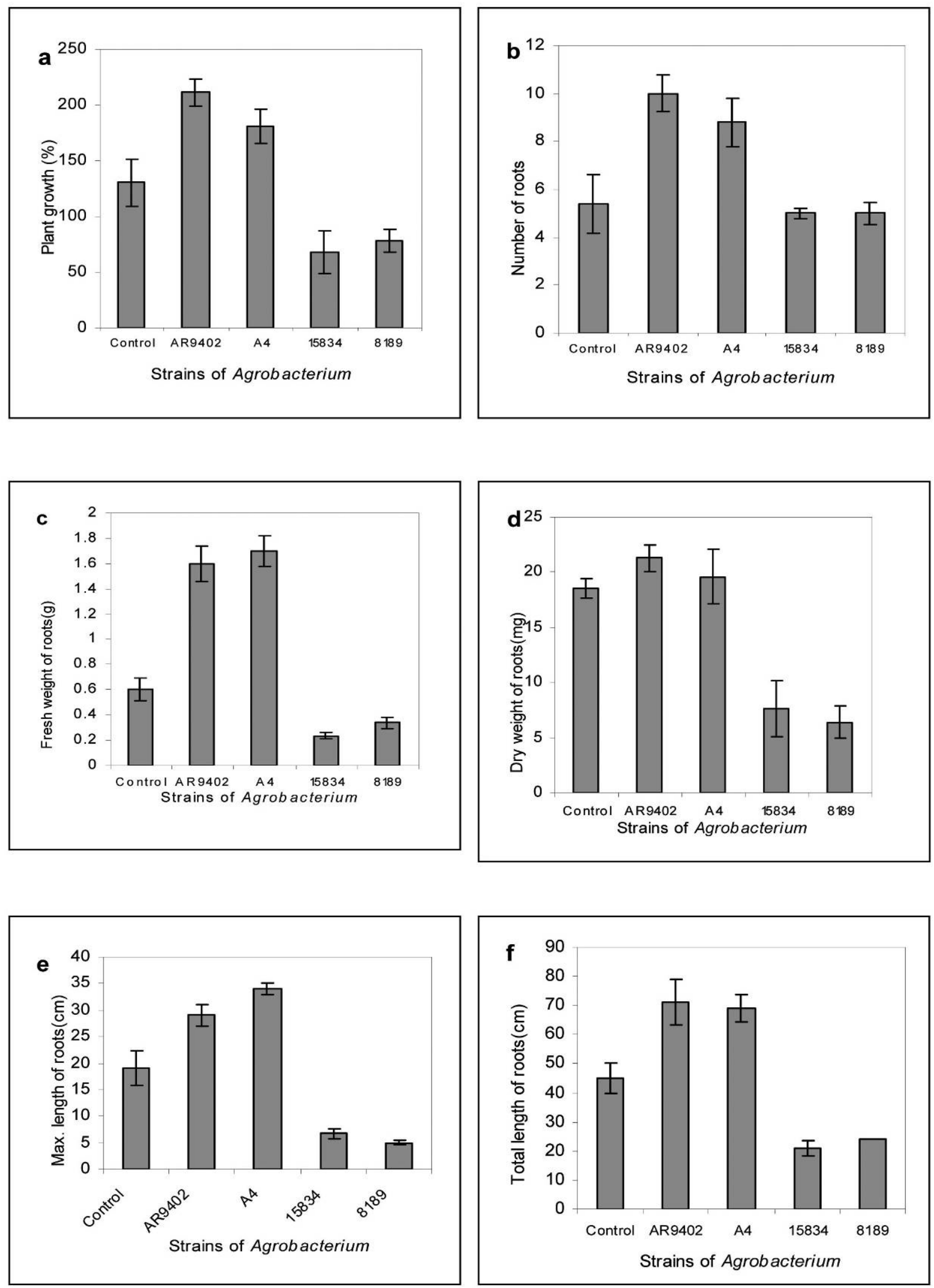

Figure 3. Growth and root biomass of in vitro banana plantlets after one month culture in MS liquid medium inoculated with strains of Agrobacterium: a (percentage of growth), b (number of roots), c (fresh weight of roots), d (dry weight of roots), and e (maximum length of roots) and $\mathrm{f}$ (total length of roots). Bars show means $\pm \mathrm{SD}$ of ten replications $(\mathrm{P}=0.05$, $\mathrm{n}=10)$. 


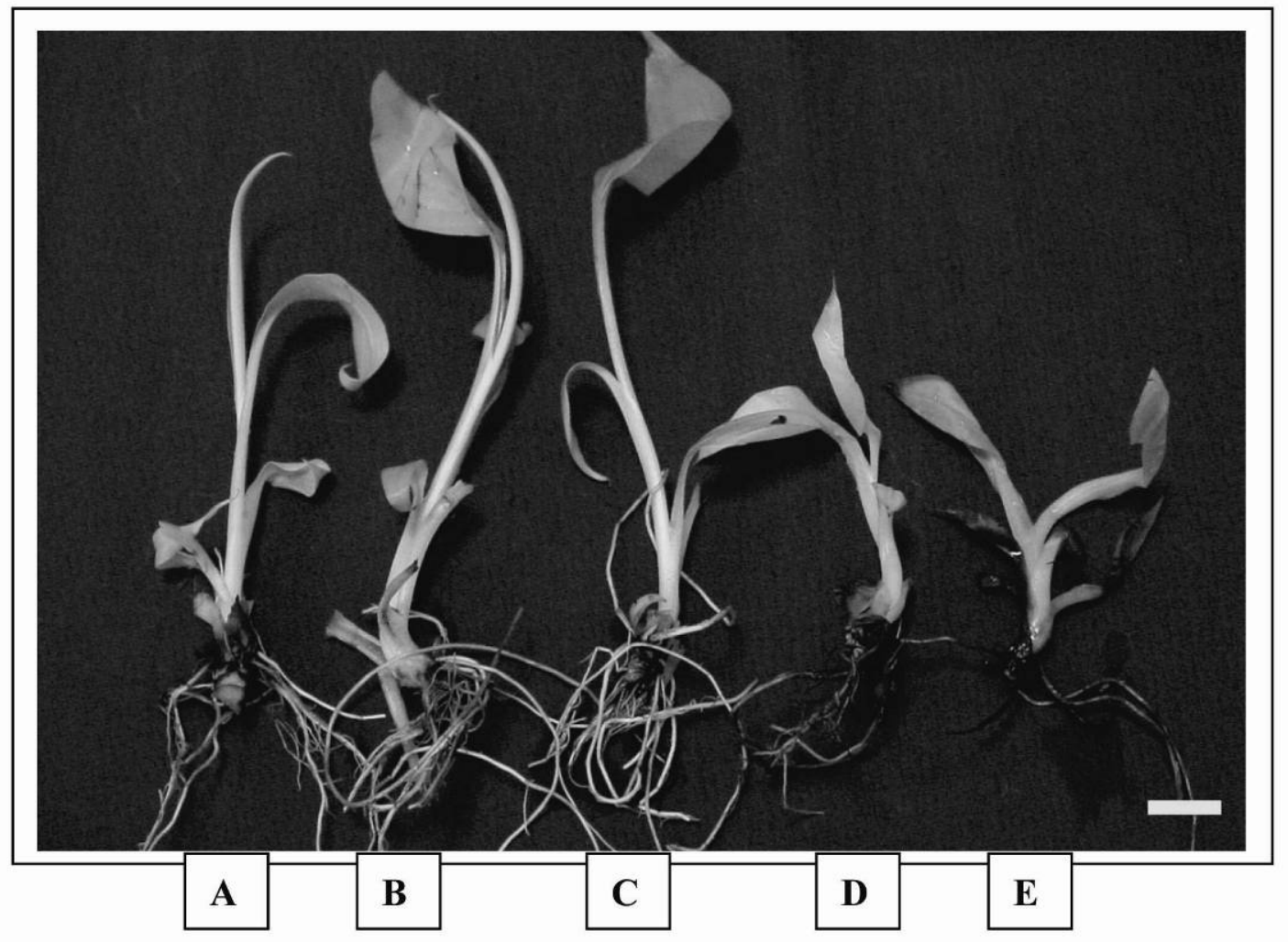

Figure 4. Growth of in vitro banana plantlets after one month culture in MS liquid medium inoculated with agrobacterial: A (control), B (Agrobacterium strains AR9240), C (Agrobacterium strains A4), D (Agrobacterium strains 16758) and E (Agrobacterium strains 14356 ). Bar represents $10 \mathrm{~mm}$. 
Panel a

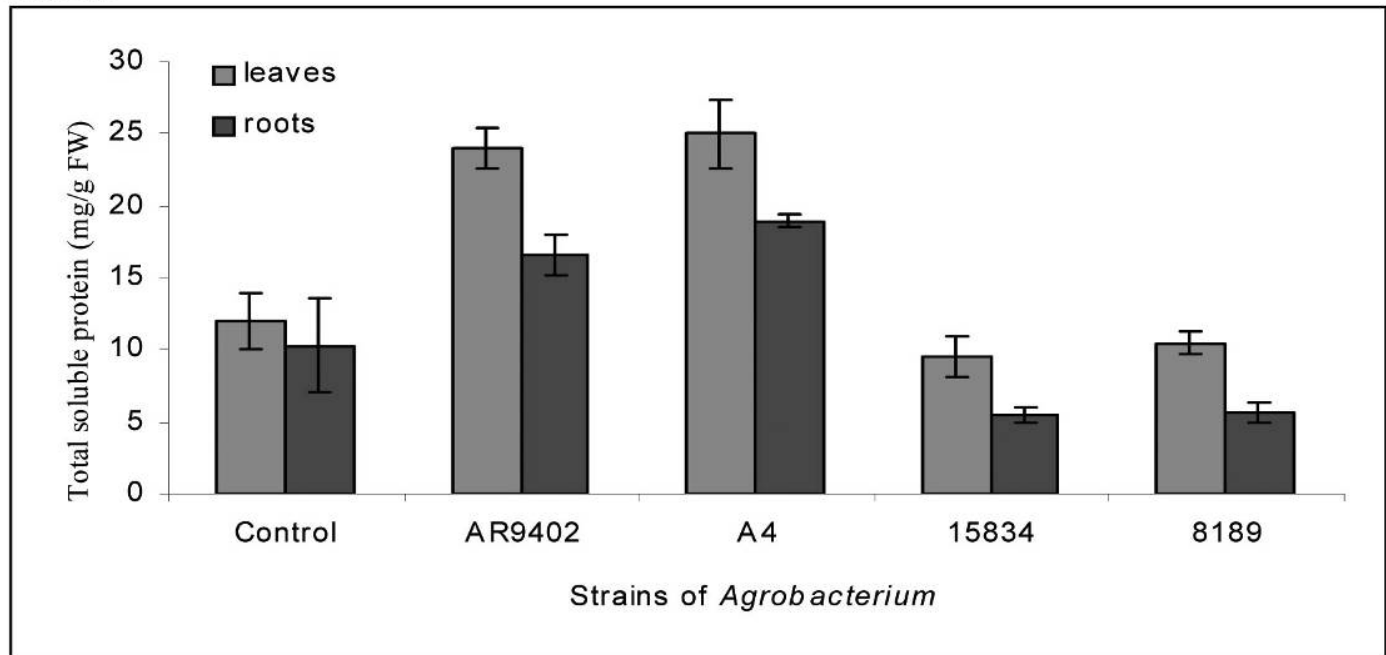

\section{Panel b}

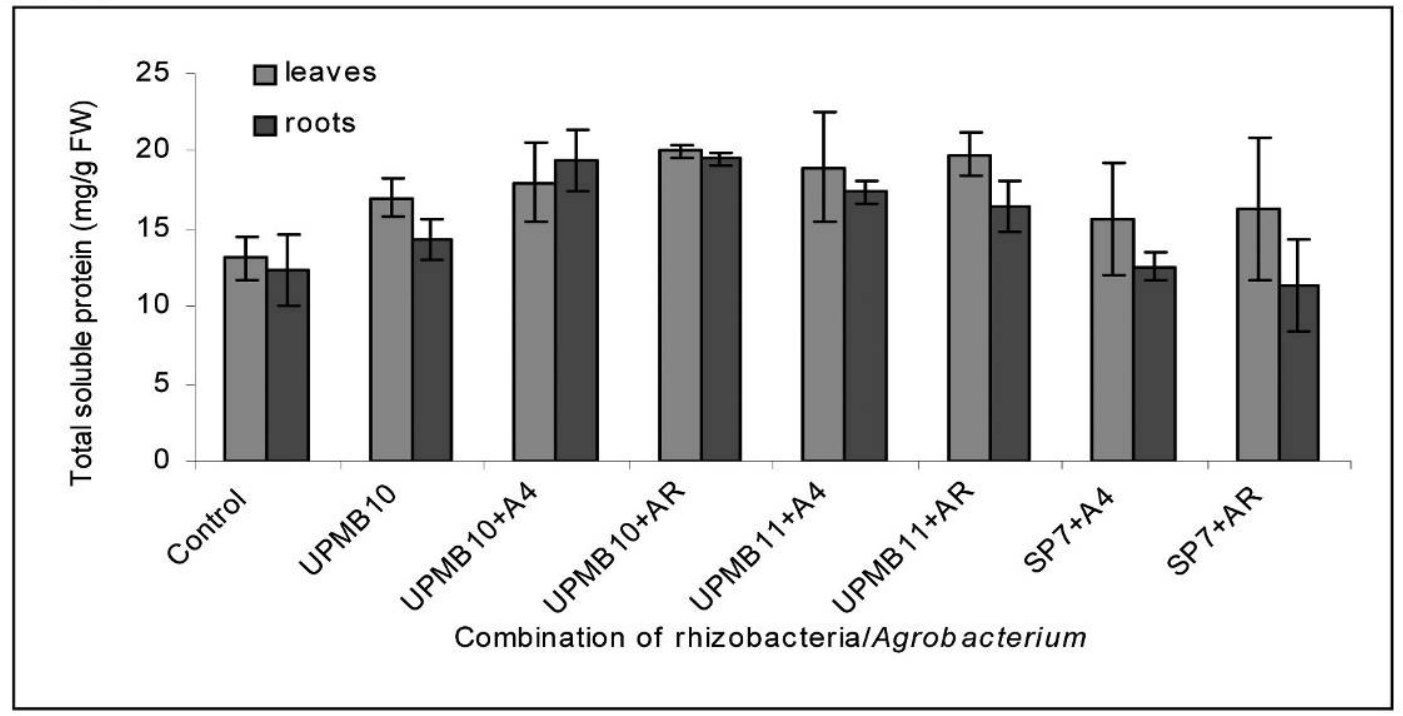

\section{Panel c}

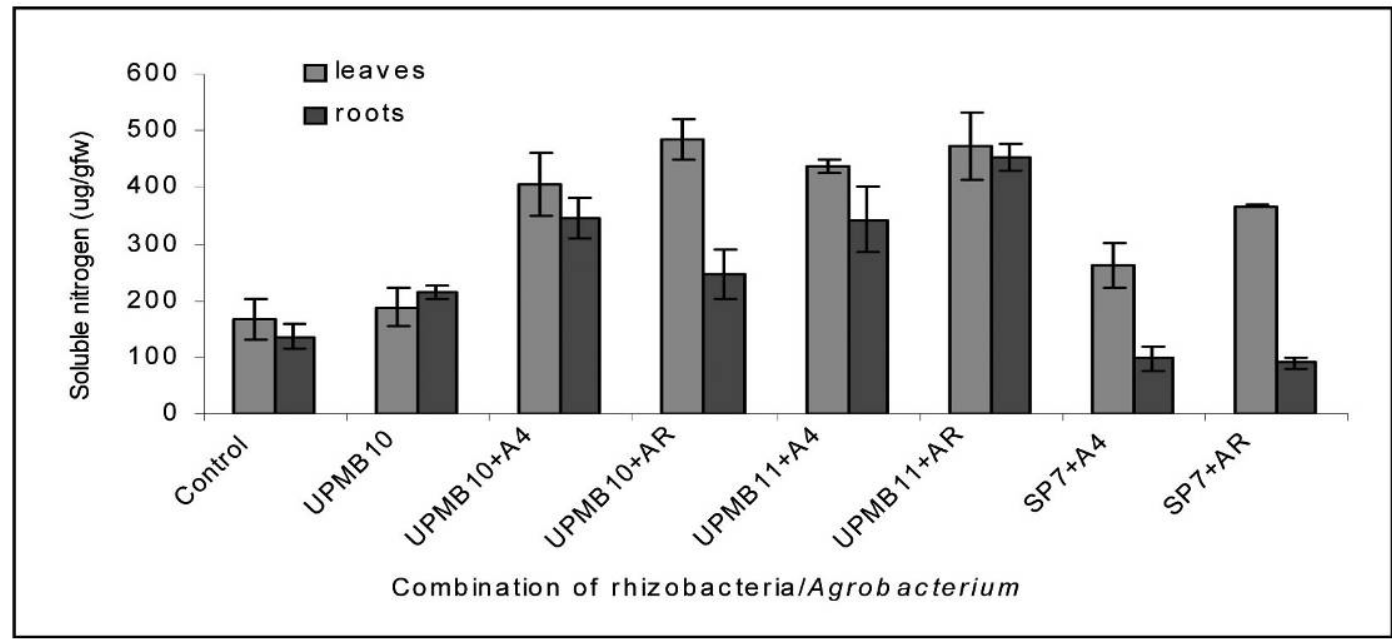

Figure 5. Soluble protein content of in vitro banana plantlets after one month culture in MS liquid medium inoculated with respective bacterial treatment: a (rhizobacteria), b (Agrobacterium) and c (co-inoculation with rhizobacteria and Agrobacterium). Bars show means SD of ten replications $(\mathrm{P}=0.05, \mathrm{n}=10)$. 


\section{Panel a}

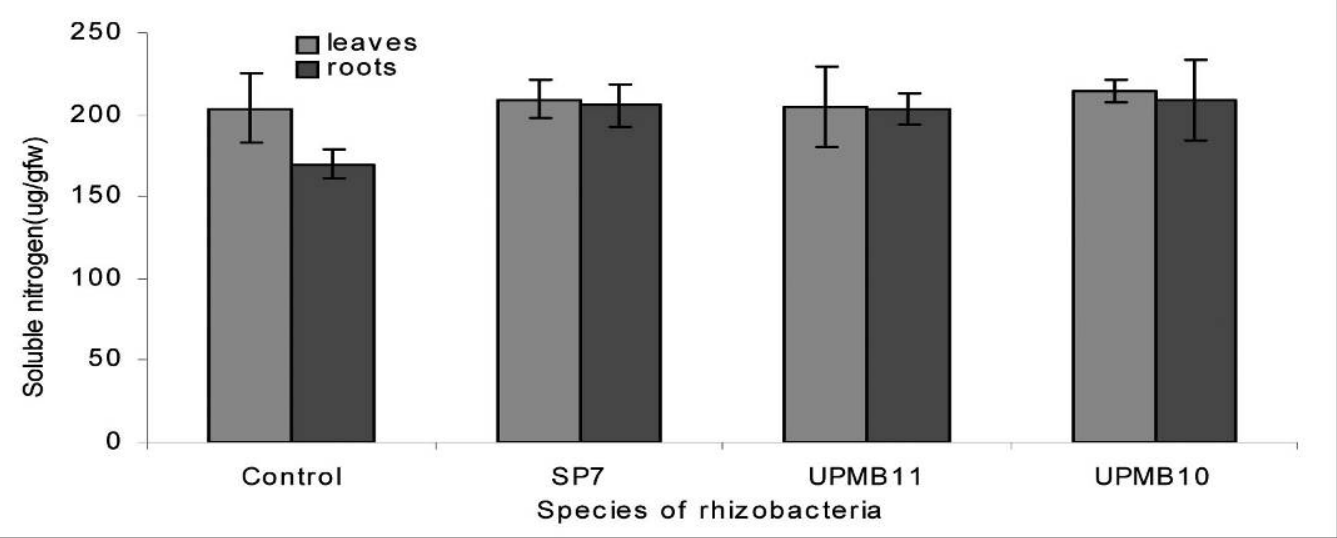

\section{Panel b}

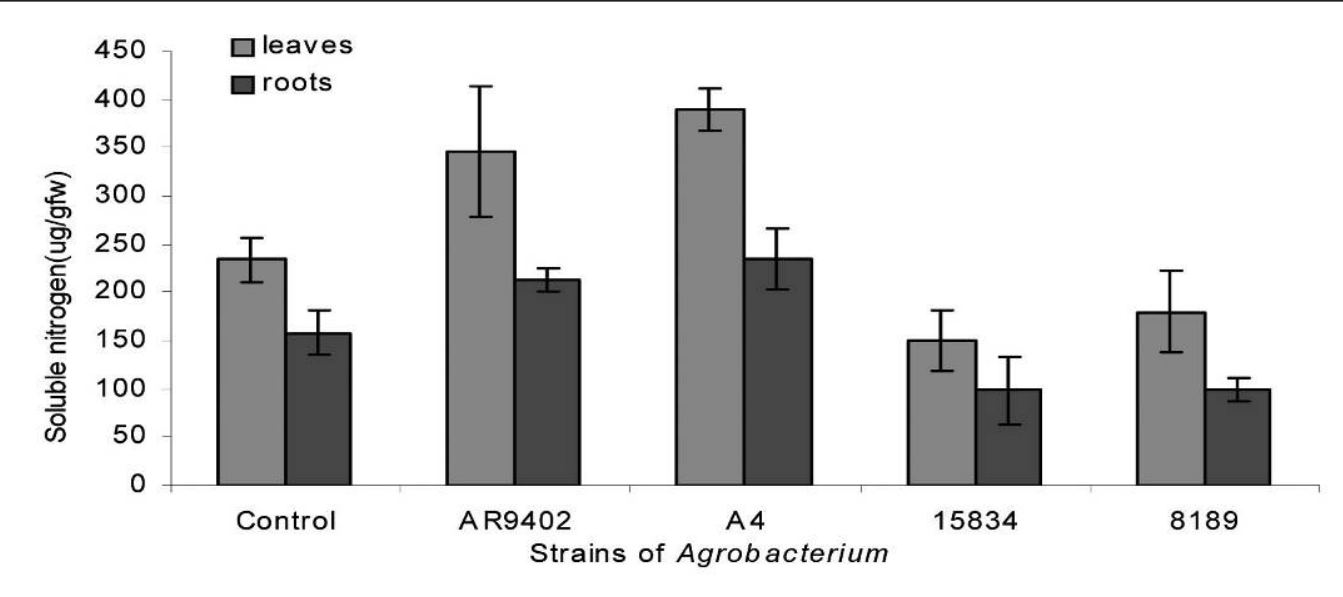

\section{Panel c}

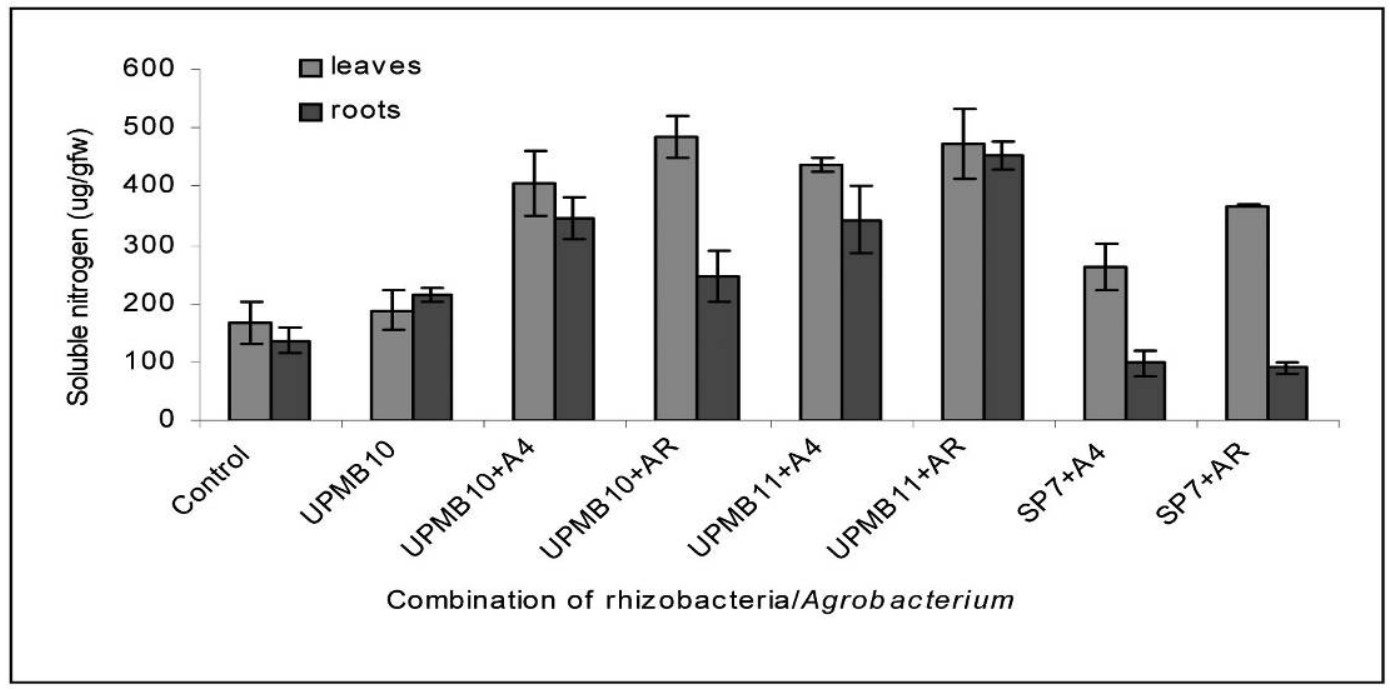

Figure 6. Soluble nitrogen content in part of banana plantlets after one month inoculated with respective bacterial treatments: a (rhizobacteria), b (Agrobacterium) and c (co-inoculation of Agrobacterium) in MS liquid medium. Bars show means $\mathrm{SD}$ of ten replications $(\mathrm{P}=0.05, \mathrm{n}=10)$. 


\section{Panel a}

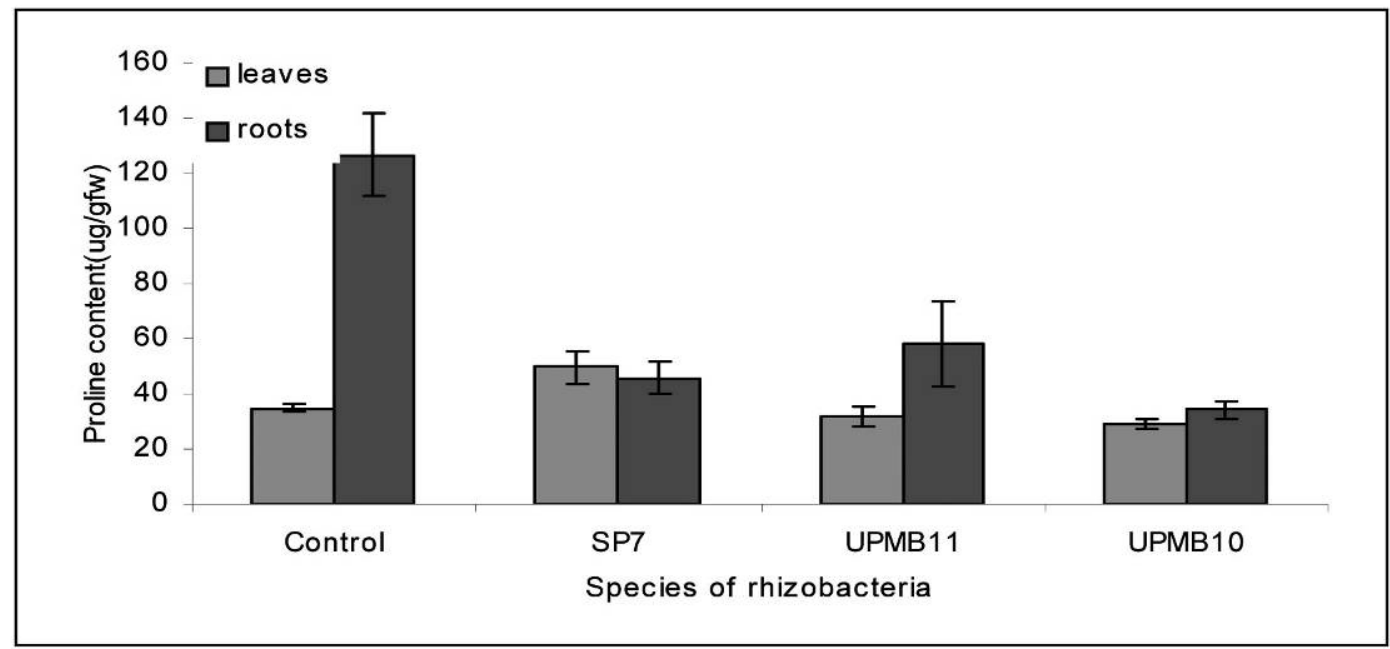

\section{Panel b}

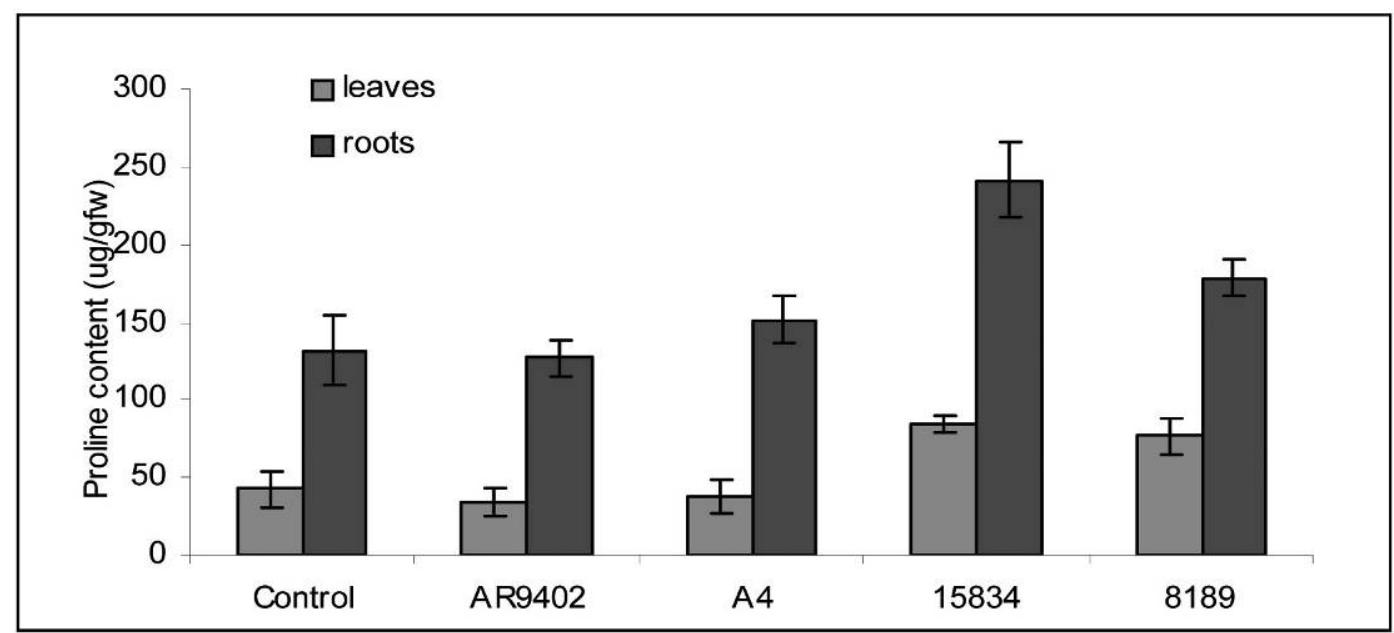

\section{Panel c}

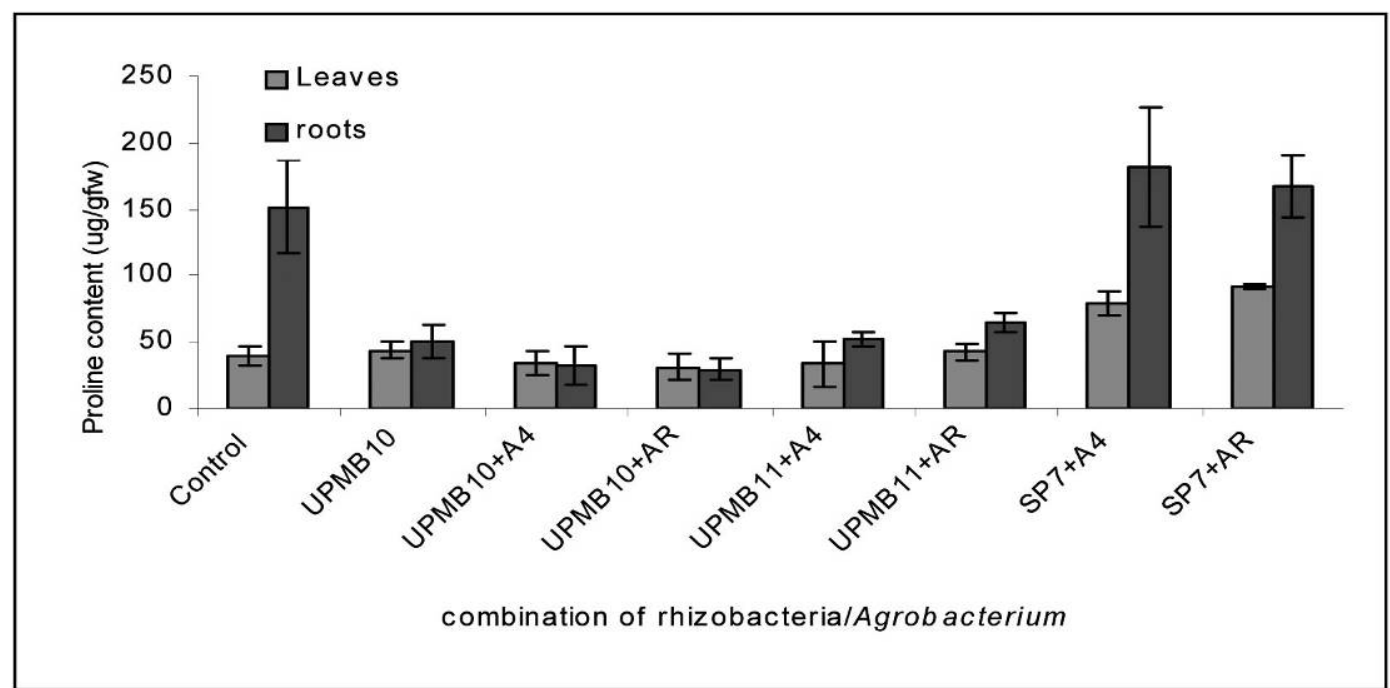

Figure 7. Change of proline content of in vitro banana plantlets for one month culture in MS liquid medium in the presence of respective bacterial treatment: a (rhizobacteria), $\mathrm{b}$ (Agrobacterium) and c (co-inoculation of rhizobacteria and Agrobacterium). Bars show means $\mathrm{SD}$ of ten replications $(\mathrm{P}=0.05, \mathrm{n}=10)$. 
Panel a

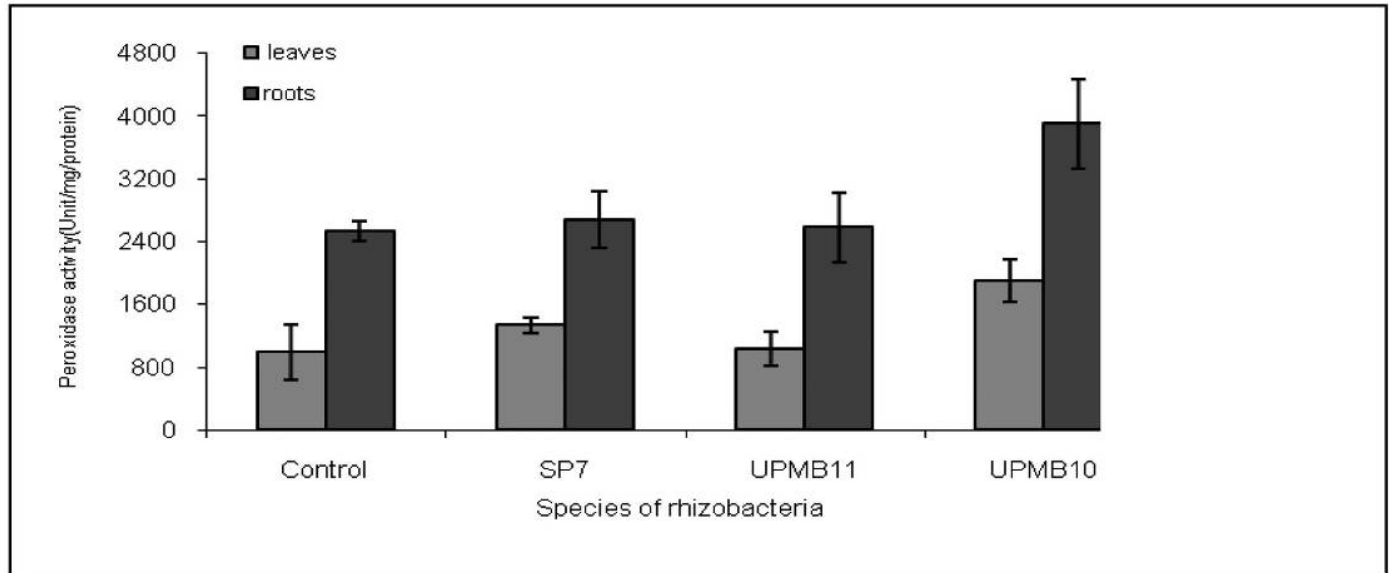

\section{Panel b}

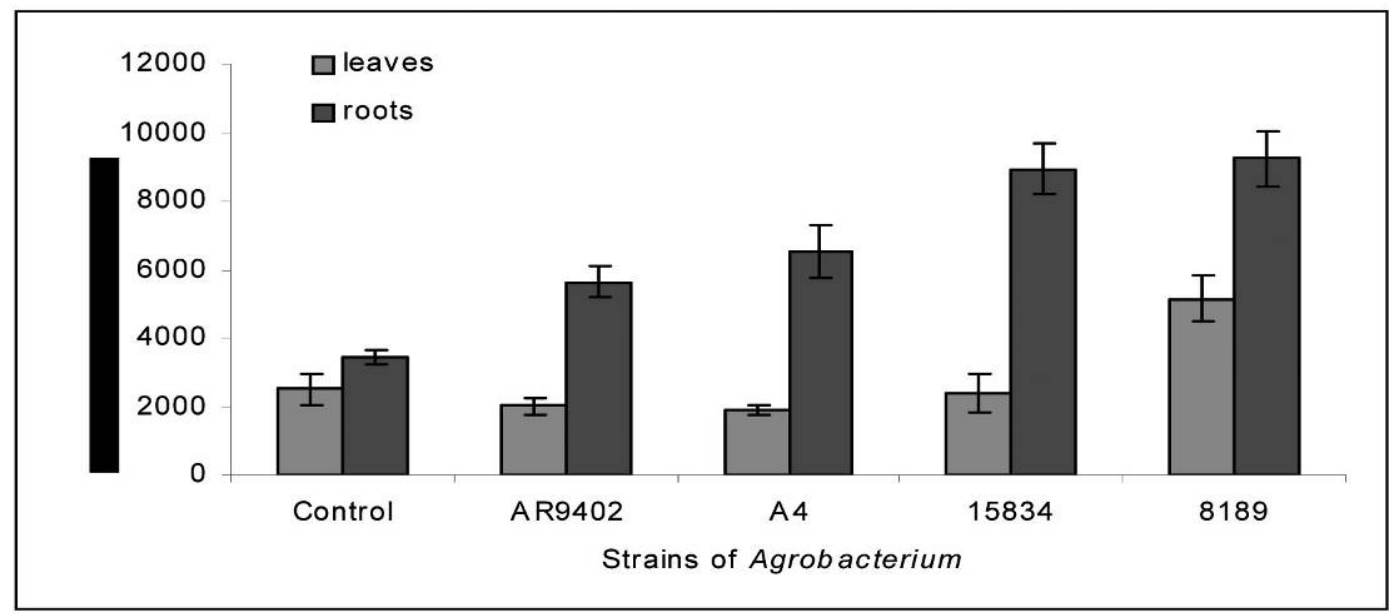

Panel C

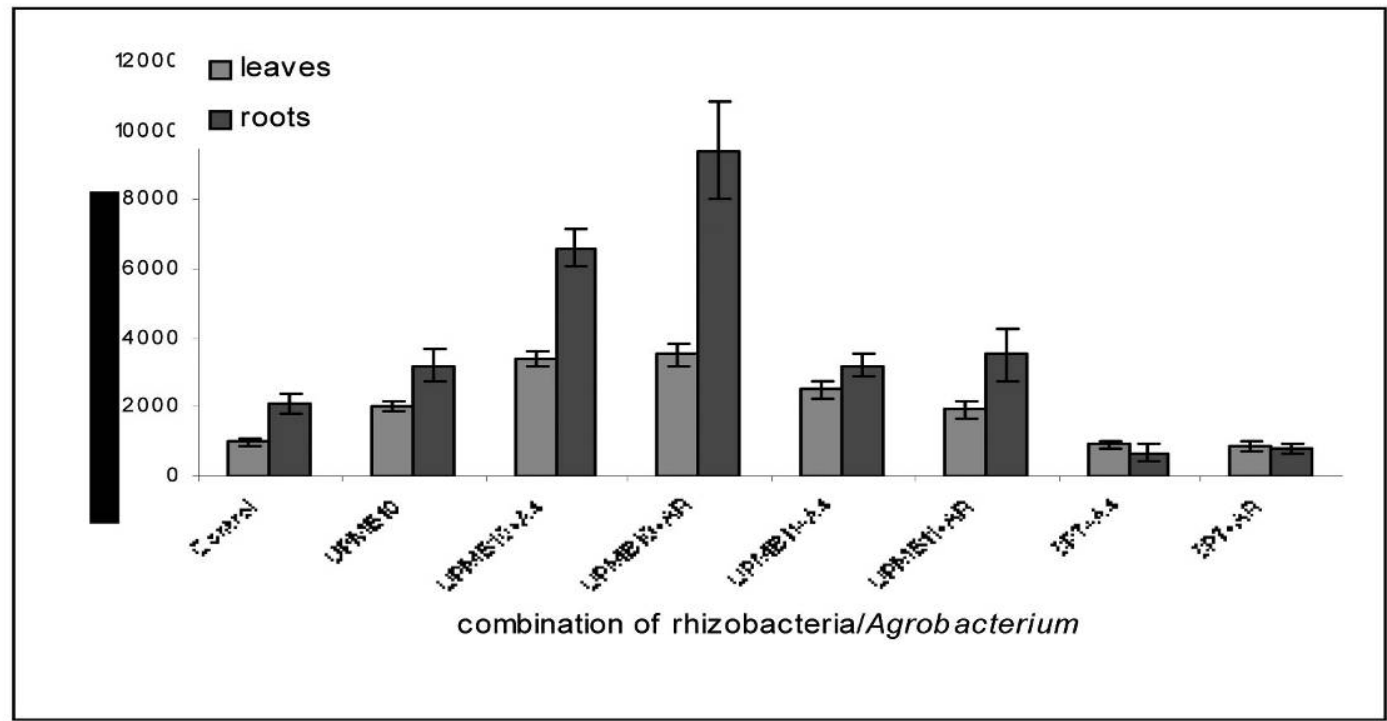

Figure 8. Change of peroxidase activity on in vitro banana plantlets after one month culture in MS liquid medium inoculated with respective bacterial treatment: a (rhizobacteria), b (Agrobacterium) and c (co-inoculation of rhizobacteria and Agrobacterium). Bars show means $\mathrm{SD}$ of ten replications $(\mathrm{P}=0.05, \mathrm{n}=10)$. 


\section{Panel a}

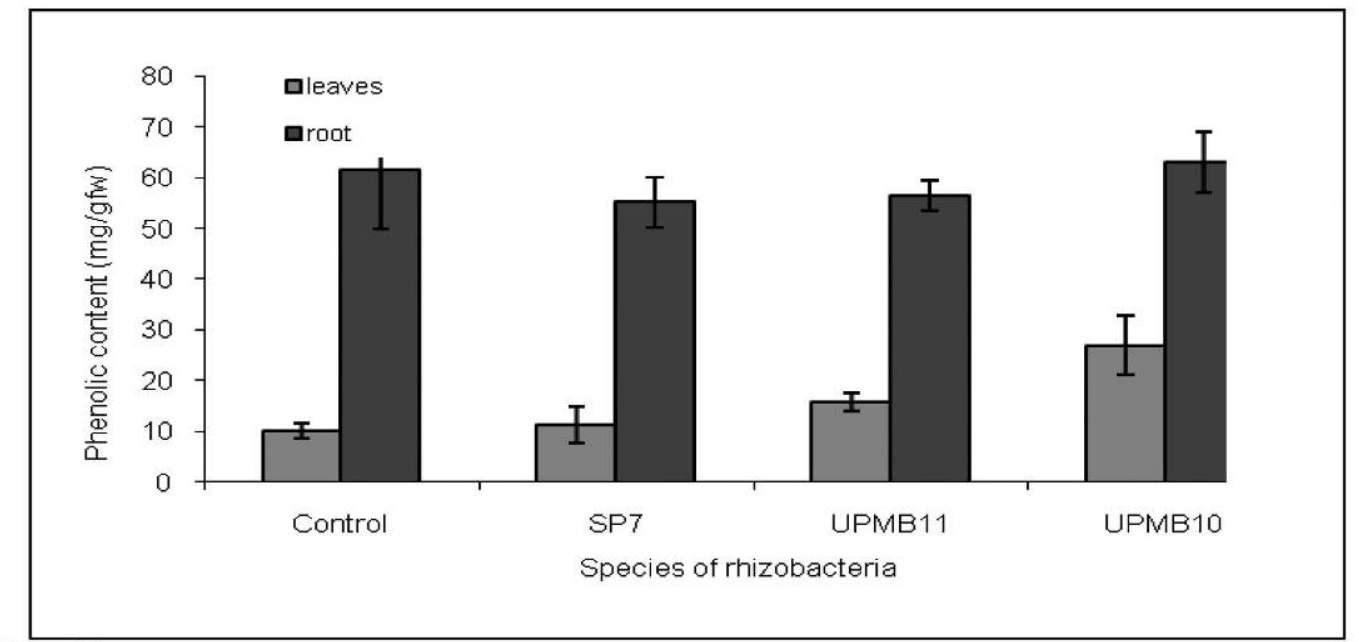

\section{Panel b}

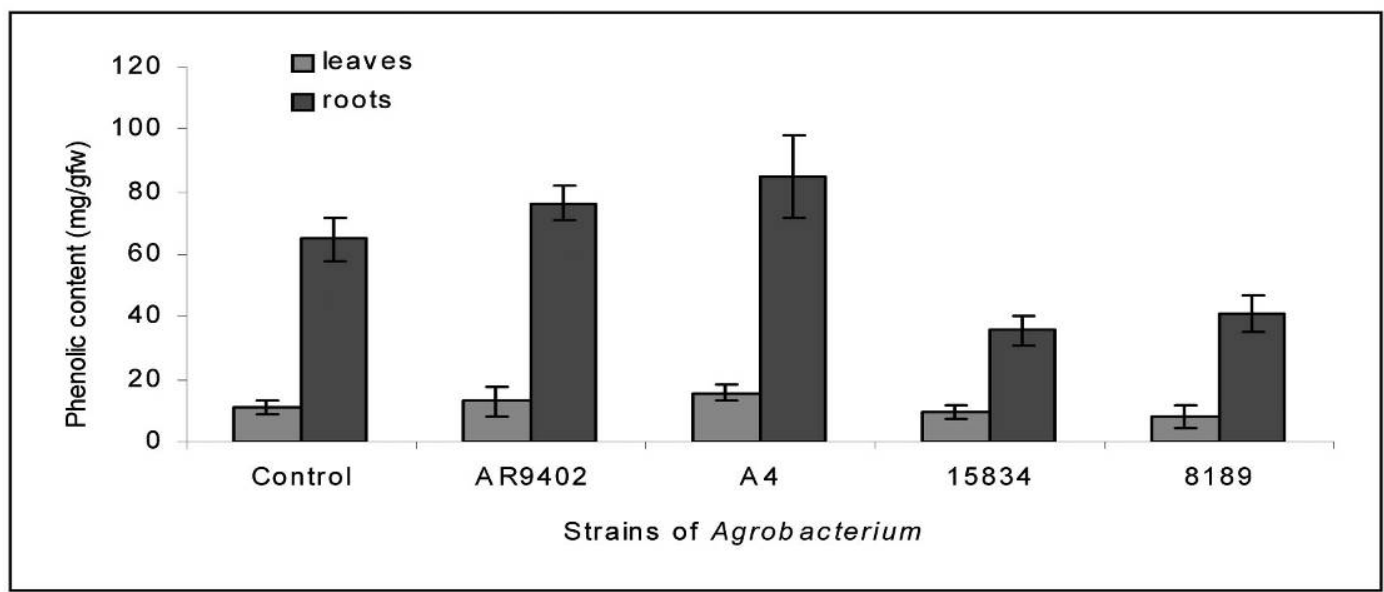

\section{Panel c}

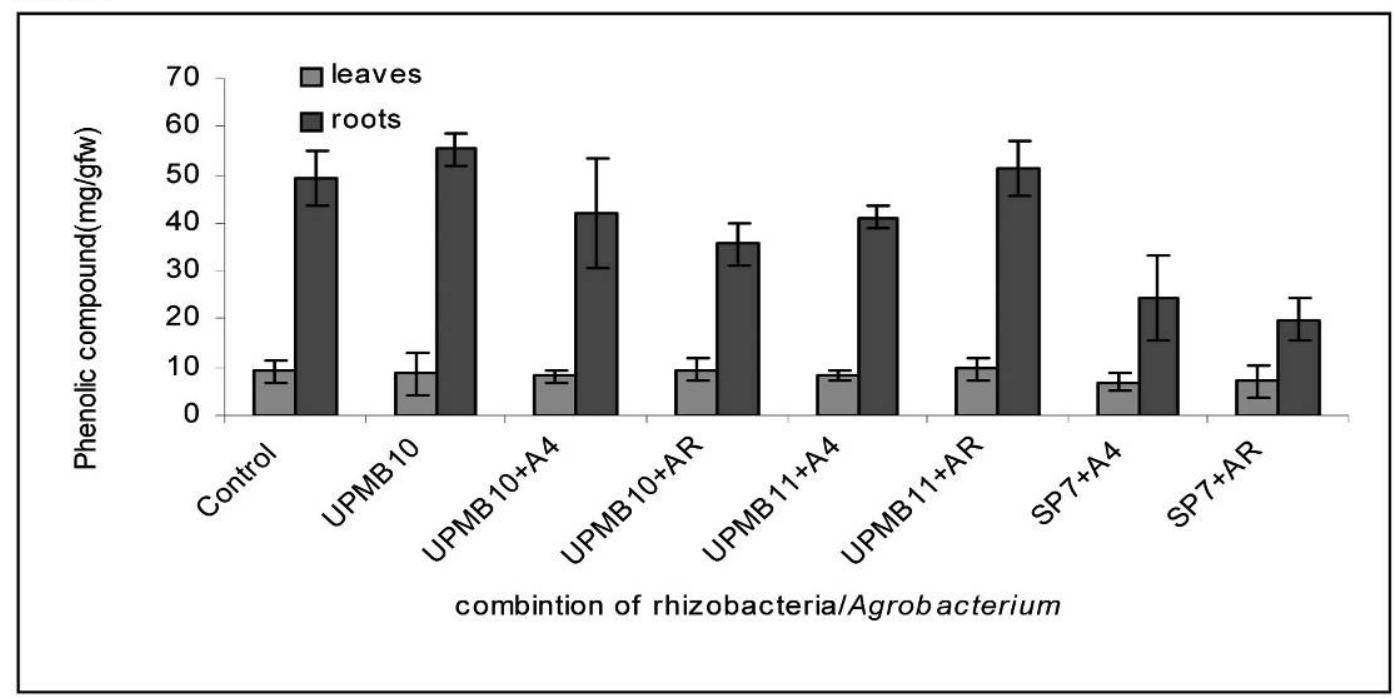

Figure 9. Effect of bacteria: a (rhizobacteria, b (Agrobacterium) and c (co-inoculation of rhizobacteria and Agrobacterium) inoculation on changes of total phenolic compound of in vitro banana plantlets after one month culture in MS liquid medium. Bars show means $\mathrm{SD}$ of ten replications $(\mathrm{P}=0.05, \mathrm{n}=10)$. 


\section{Panel a}

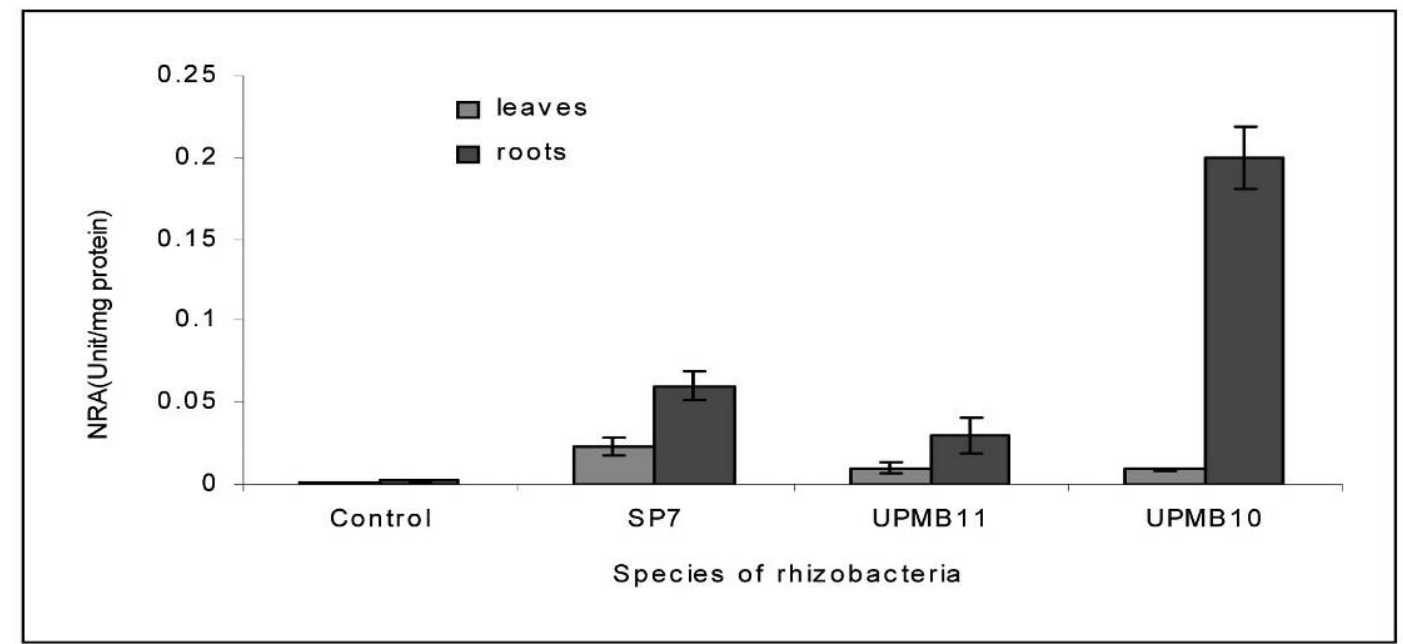

\section{Panel b}

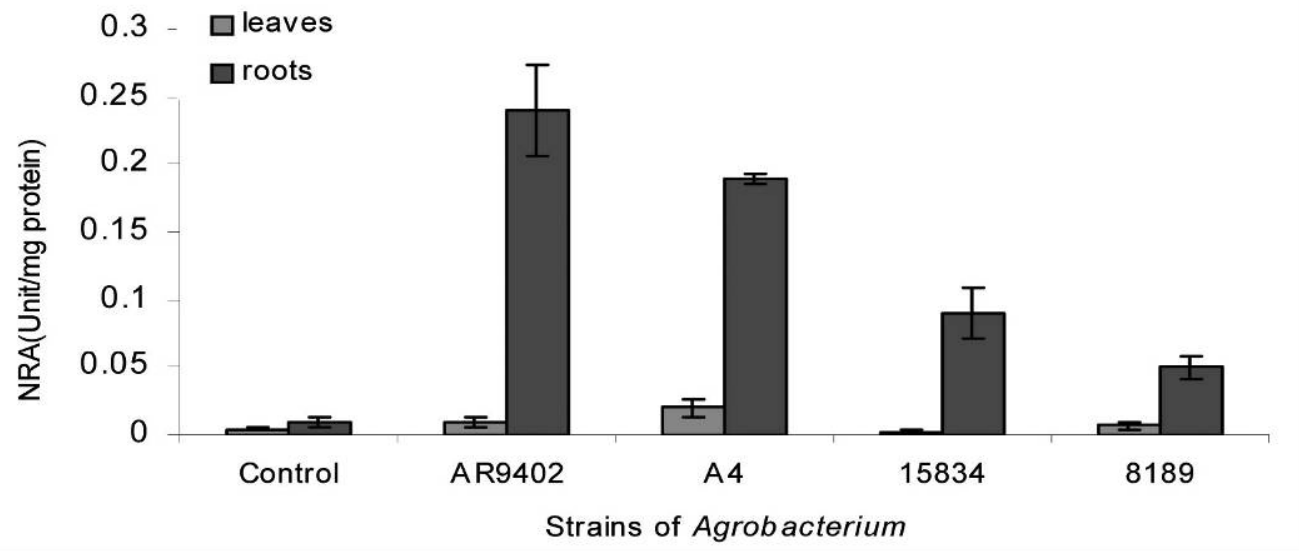

Panel c

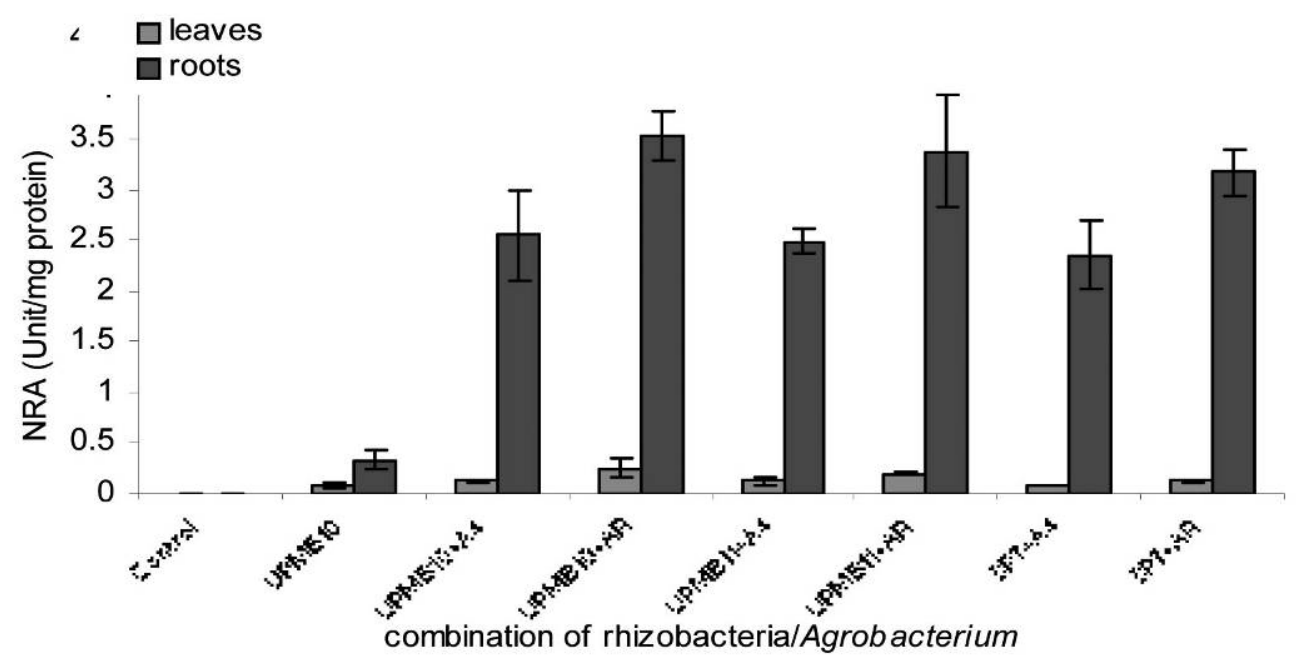

Figure 10. Change of nitrate reductase activity of in vitro banana plantlets after one month culture in MS liquid medium inoculated with respective bacterial treatment: a (rhizobacteria), b (Agrobacteria) and c (co-inoculation of rhizobacteria and Agrobacterium). Bars show means $\mathrm{SD}$ of ten replications $(\mathrm{P}=0.05, \mathrm{n}=10)$. 


\section{Panel a}

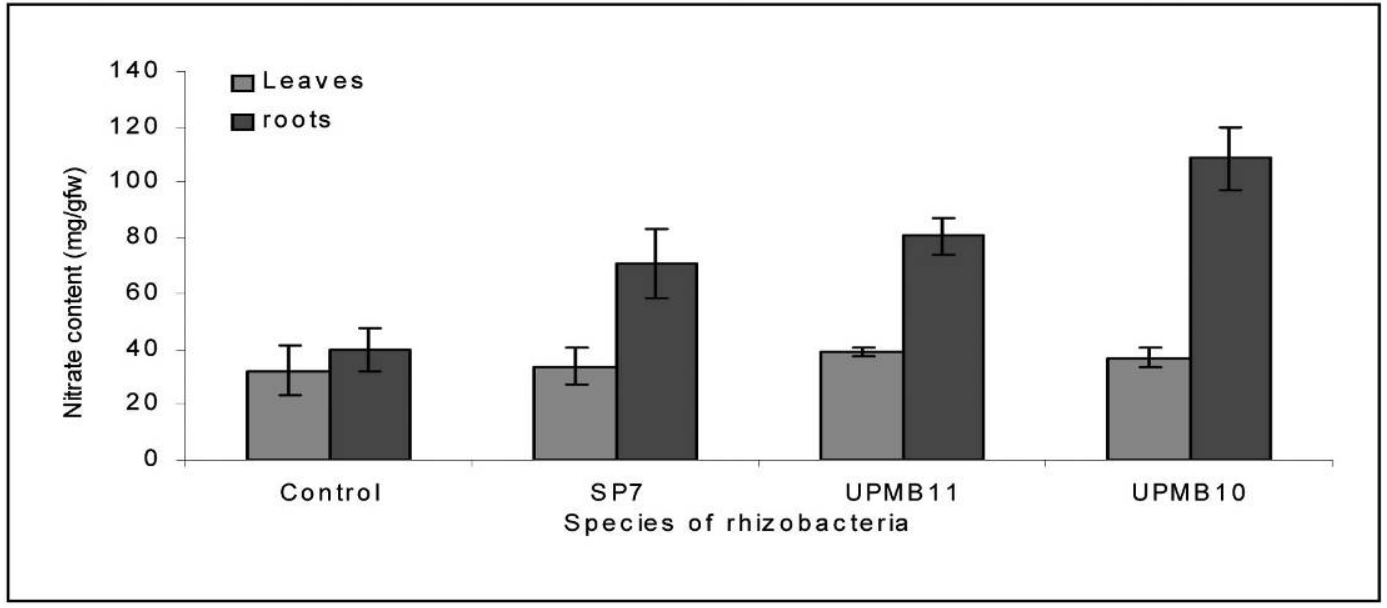

Panel b

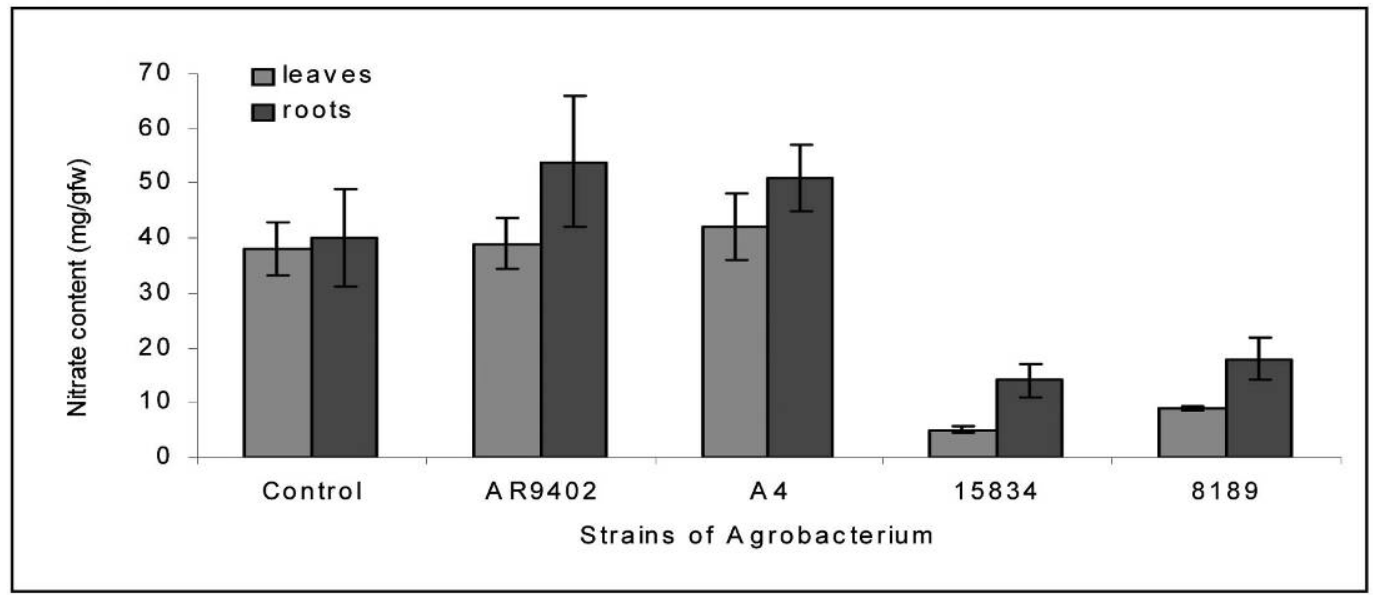

\section{Panel c}

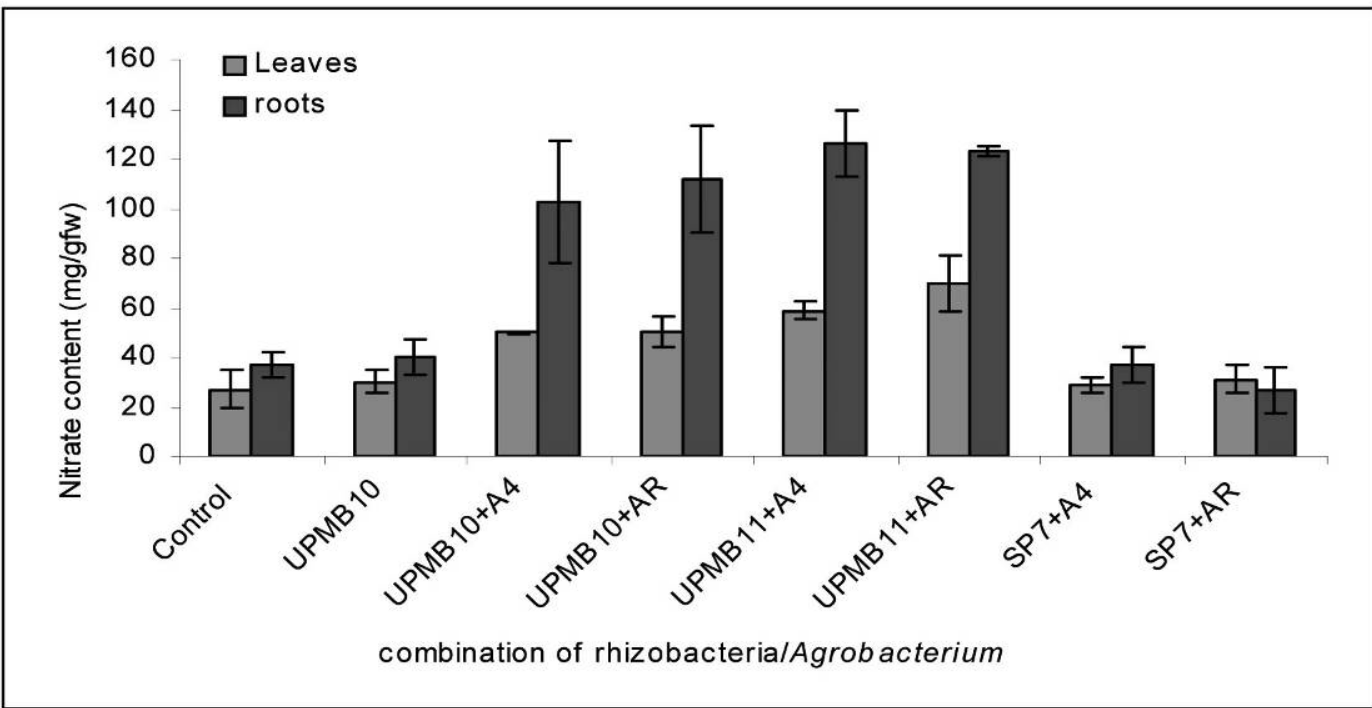

Figure 11. Effect of respective bacterial: a (rhizobacteria), b (Agrobacterium ) and c (co-inoculation of rhizobacteria and Agrobacterium) inoculation on nitrate content of in vitro banana plantlets for one month culture in MS liquid medium. Bars show means $\mathrm{SD}$ of ten replications $(\mathrm{P}=0.05, \mathrm{n}=10)$. 
Panel A

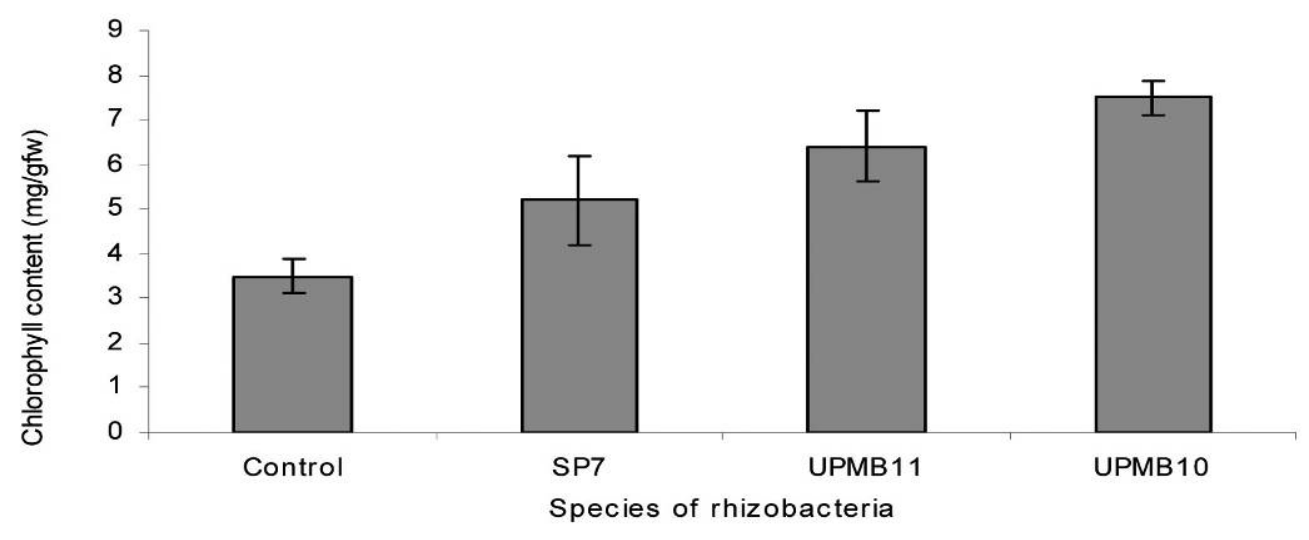

\section{Panel B}

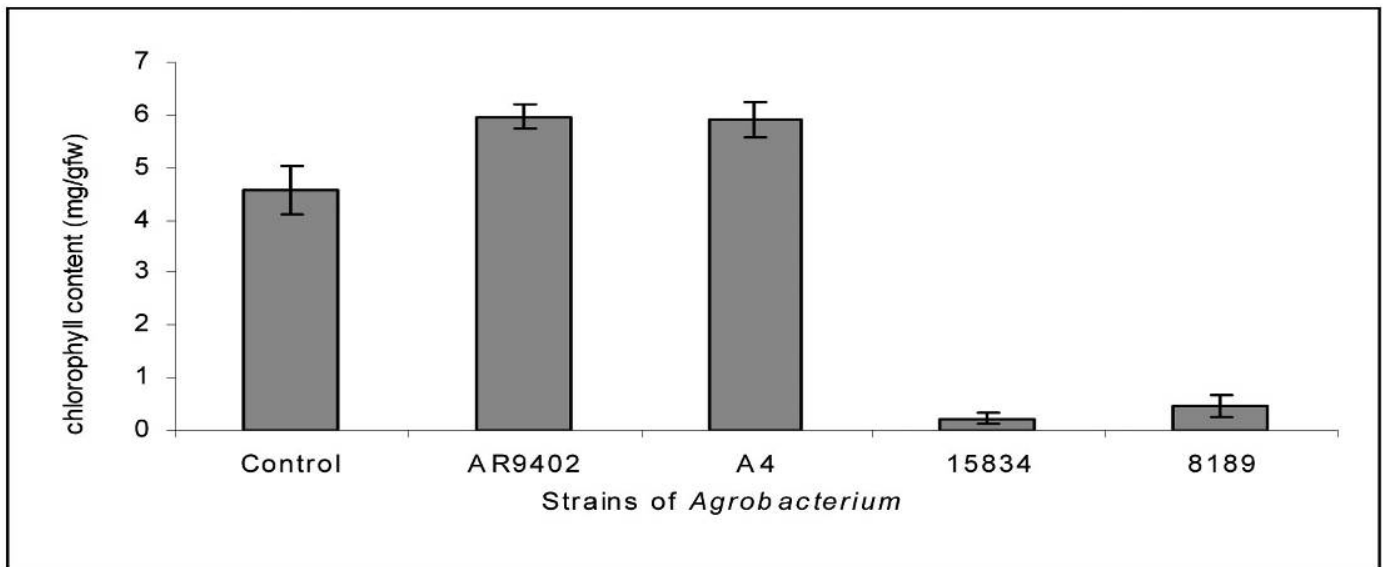

\section{Panel C}

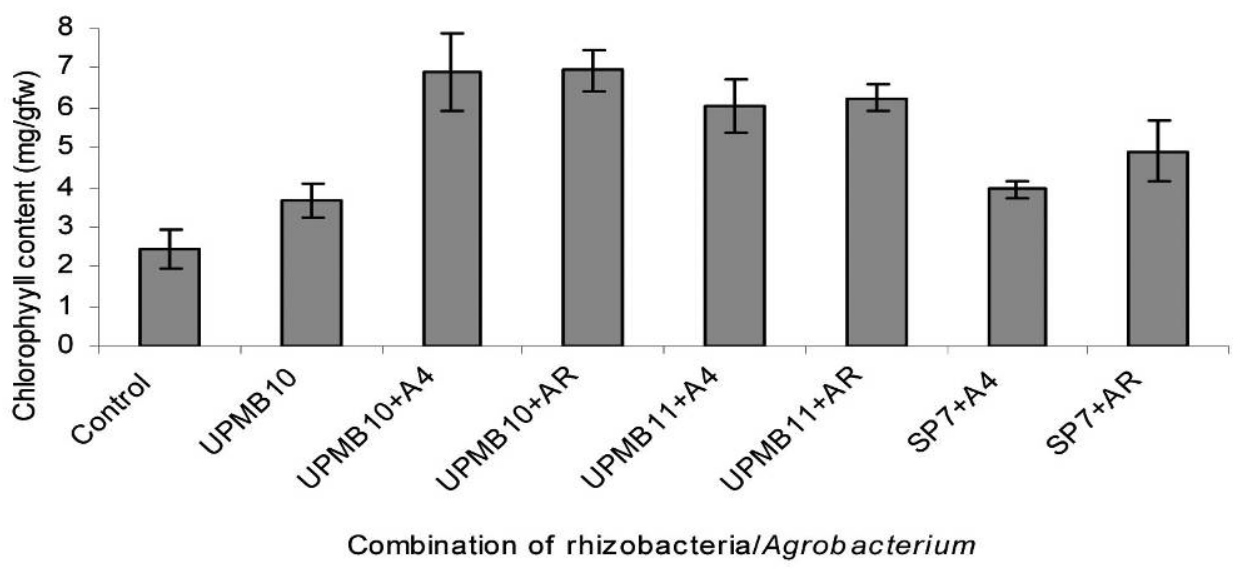

Figure 12. Chlorophyll content of in in vitro banana plantlets after one month culture in MS liquid medium inoculated with respective bacterial treatment: a ( rhizobacteria), b (Agrobacterium) and c (co-inoculation of rhizobacteria and Agrobacterium). Bars show means $\mathrm{SD}$ of ten replications $(\mathrm{P}=0.05, \mathrm{n}=10)$. 


\section{Panel a}

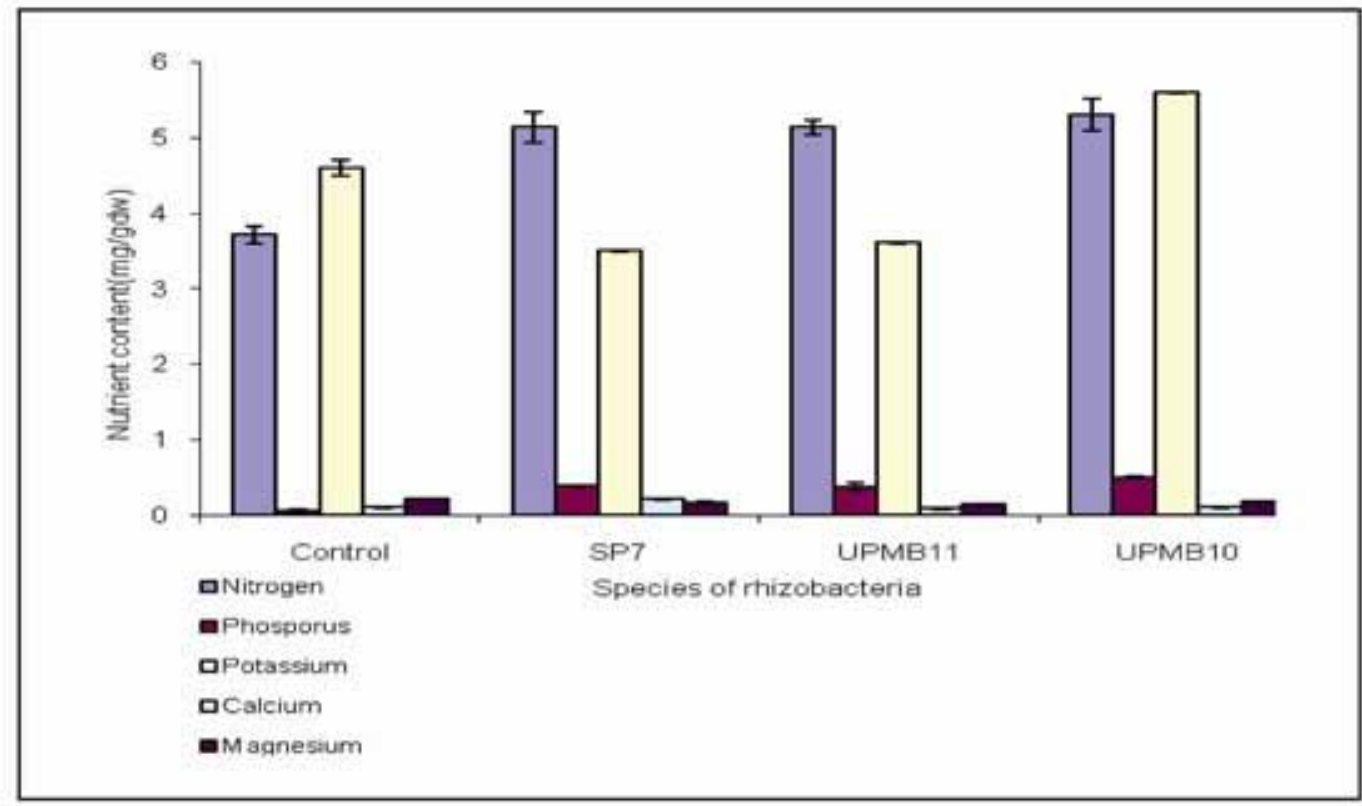

\section{Panel b}

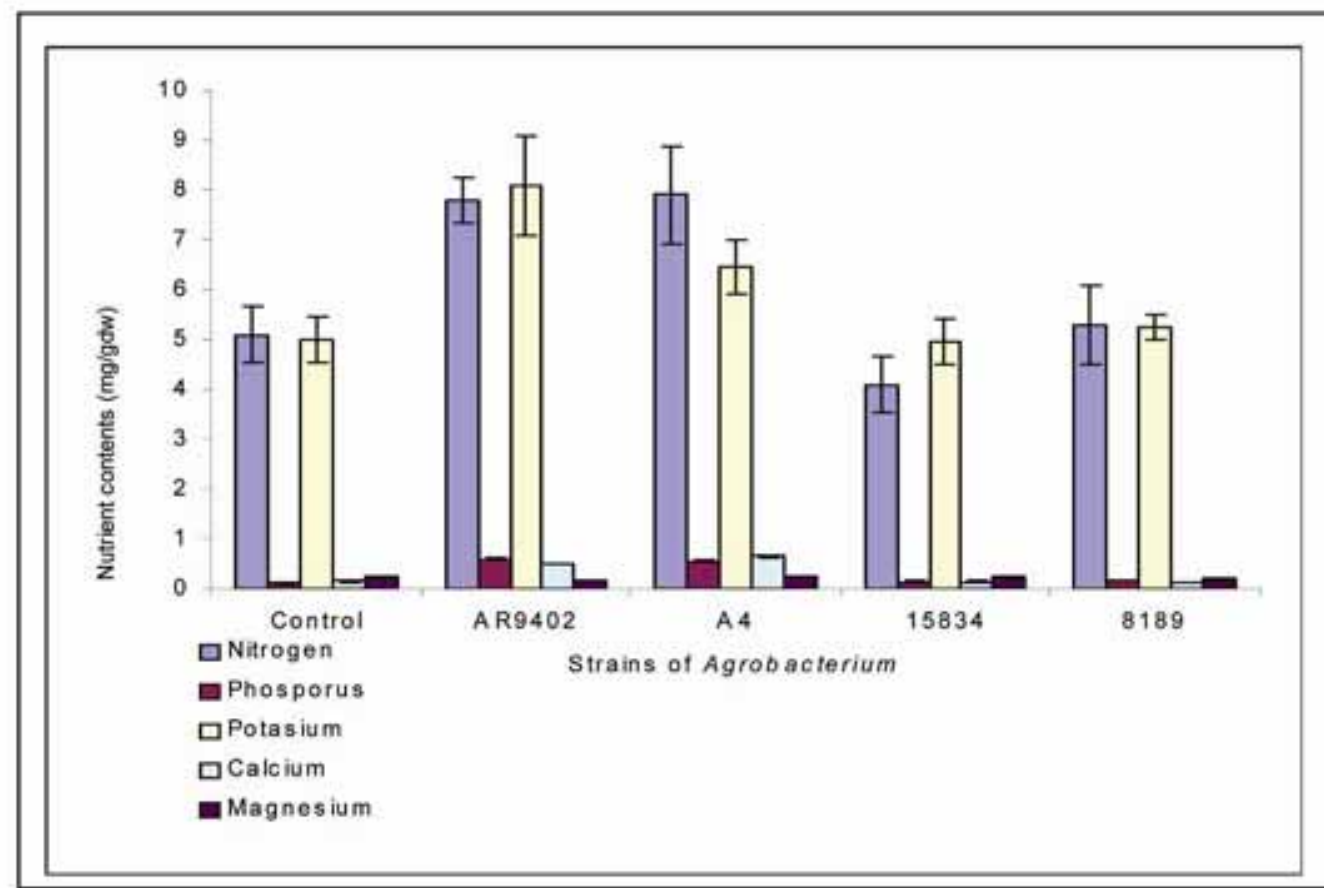

Figure 13. Effect of: a (rhizobacteria), and b (Agrobacterium) on nutrient content of in vitro banana plantlets after one month culture in MS liquid medium. Bars show means $\mathrm{SD}$ of ten replications $(\mathrm{P}=0.05, \mathrm{n}=10)$. 